Review

\title{
Blocking the FGF/FGFR system as a "two-compartment" antiangiogenic/antitumor approach in cancer therapy
}

\author{
Arianna Giacomini, Paola Chiodelli, Sara Matarazzo, Marco Rusnati, Marco Presta, \\ Roberto Ronca*
}

Department of Molecular and Translational Medicine, University of Brescia, 25123 Brescia, Italy

\section{A R T I C L E I N F O}

\section{Article history:}

Received 22 January 2016

Received in revised form 15 March 2016

Accepted 16 March 2016

Available online 22 March 2016

\section{Keywords:}

Angiogenesis

Cancer

Cancer therapy

FGF

FGFR

Stroma

Therapeutic target

\begin{abstract}
A B S T R A C T
Fibroblast growth factors (FGFs) are a family of pleiotropic factors produced by stromal and parenchymal tumor cells. Even though FGFs have been firstly characterized as angiogenic factors, they exert autocrine and paracrine functions not only on endothelial cells but also on tumor cells and other stromal components. Thus, the FGF/FGF receptor (FGFR) pathway may represent a key player in tumor growth by regulating the complex cross-talk between stromal and tumor compartments.

The ligand dependent or independent activation of the FGF/FGFR system by gene upregulation, oncogenic mutation or amplification occurs in a variety of human tumors and is implicated in various key steps of tumor growth and progression. In addition, FGF/FGFR activation has been described as a mechanism of tumor escape in response to antiangiogenic/anti-VEGF therapies.

Experimental and clinical evidences provide a compelling biologic rationale for the development of anti-FGF/FGFR targeting agents in cancer therapy. However, the development of drugs specifically targeting the FGF/FGFR pathway proved to be difficult, also due to the high redundancy and pleiotropic effects of FGF and FGFR family members. On the other hand, the possibility to develop "two-compartment" targeting agents endowed with both antiangiogenic and antitumor activities remains promising.

Here we will review the preclinical and clinical approaches and potential therapeutics currently available to block the FGF/FGFR system in human cancer.
\end{abstract}

(c) 2016 Elsevier Ltd. All rights reserved.

\section{Contents}

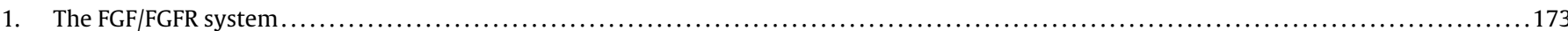

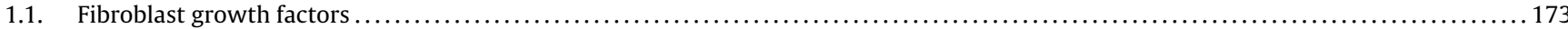

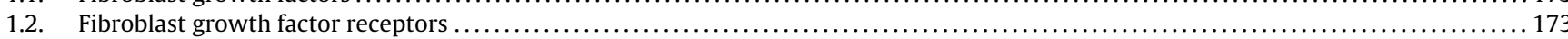

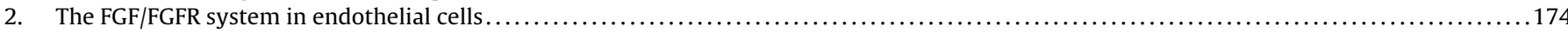

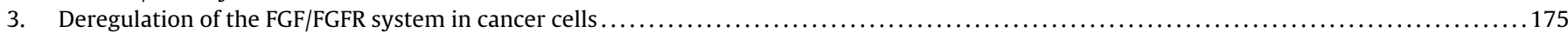

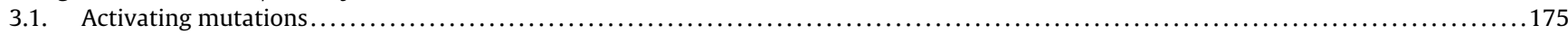

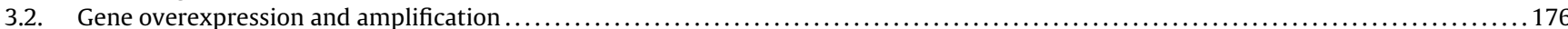

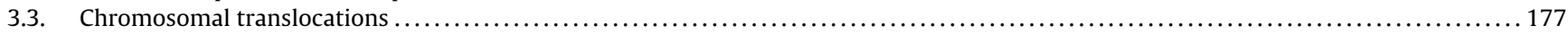

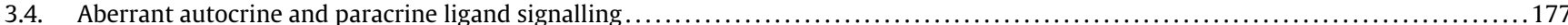

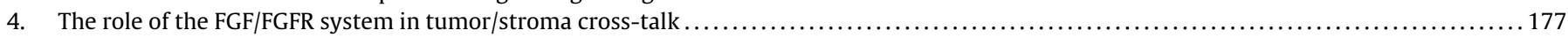

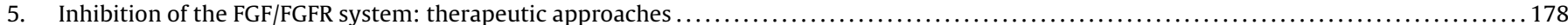

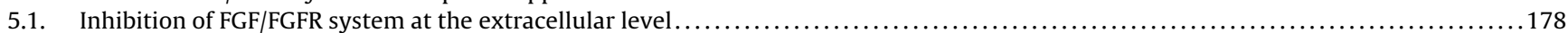

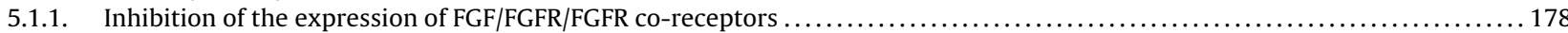

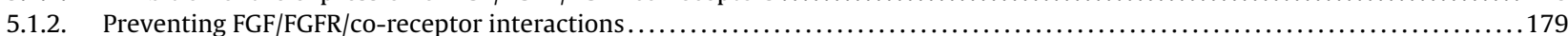

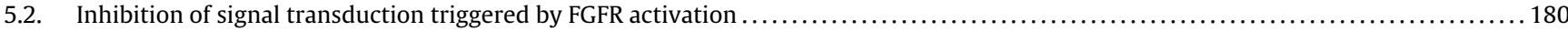

\footnotetext{
* Corresponding author at: University of Brescia, Department of Molecular and Translational Medicine, viale Europa 11, 25123 Brescia, Italy.

E-mail address: roberto.ronca@unibs.it (R. Ronca).
} 


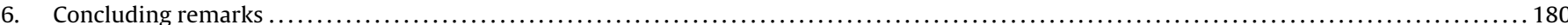

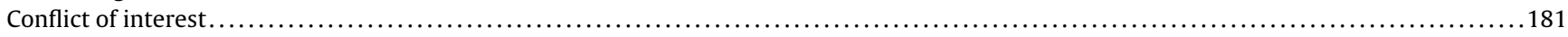

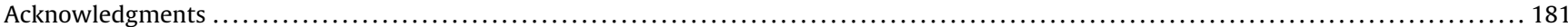

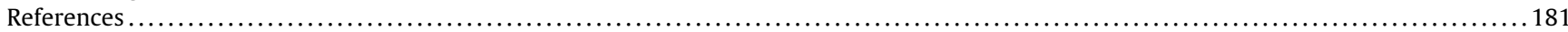

\section{The FGF/FGFR system}

\subsection{Fibroblast growth factors}

Fibroblast growth factors (FGFs) are secreted proteins that act as paracrine, autocrine or endocrine factors. The FGF family encompasses 22 members, grouped into seven subfamilies on the basis of phylogenetic analysis and sequence homology [1]. The subfamilies FGF1/2/5, FGF3/4/6, FGF7/10/22, FGF8/17/18 and FGF9/16/20 act as canonical FGFs; FGF11/12/13/14 are intracellular factors acting in an FGF receptor (FGFR) independent manner; FGF19/21/23 subfamily members function as hormones [2].

Canonical FGFs are paracrine factors that mediate their biological responses by binding to and activating tyrosine kinase (TK) FGFRs. The interaction with heparin/heparan sulfate (HS) proteoglycans (HSPGs) plays a pivotal role in mediating the biological activity of FGFs, leading to the formation of signalling FGF/FGFR/HSPG ternary complexes [3]. Moreover, HSPGs sequester FGF molecules near the site of action, providing a reservoir for the growth factor and allowing the formation of extracellular matrix (ECM)-associated FGF gradients [4].

Canonical FGFs mediate a plethora of functions during development. They are involved in patterning of germ cell layers, formation of body axes, induction of organogenesis and morphogenesis. Moreover, FGFs display homeostatic functions in the adult, being involved in tissue repair and remodelling processes. Finally, deregulation of FGF signalling can contribute to pathological diseases, including cancer. In this context, several alterations affecting the FGF/FGFR system have been reported in tumors, including gainor loss- of function, altered gene expression or changes in binding specificity [2].

Intracellular FGFs act as intracellular signalling molecules in a FGFR-independent manner; they play a major role in neuronal functions at postnatal stages by interacting with intracellular domains of voltage-gate sodium channels and with the neuronal mitogen-activated protein kinase scaffold protein islet-brain-2 [5].

Hormone-like FGFs exhibit poor affinity for HSPGs, resulting in more diffusive properties through blood circulation [6]. These FGFs depend on Klotho co-receptors (see below) to activate intracellular signalling responses [7]. FGF19 (orthologue of murine FGF15) acts as a growth/differentiation factor in the heart and brain at embryonic stages and plays a crucial role in regulating hepatic bile acid production [8]. FGF21 is a metabolic regulator of lipolysis in the white adipose tissue [9] and FGF23 acts as a physiological regulator of phosphate and active vitamin-D blood levels [10].

The wide-ranging biological roles of FGFs, the variety of activated signalling pathways and the complex and dynamic expression of FGF ligands and receptors implies that the FGF/FGFR system must be tightly regulated.

\subsection{Fibroblast growth factor receptors}

In mammals, FGFRs are encoded by four distinct genes (FGFR14). FGFRs consist of three extracellular immunoglobulin-like (Ig) domains (D1-3), a single transmembrane helix domain and an intracellular TK domain [11]. D2 and D3 domains are responsible for FGF binding. FGFRs show diverse specificities for FGF ligands. In addition, alternative splicing of the D3 domain that may occur in FGFR1, 2 and 3, but not in FGFR4, generates "IIIb" and "IIIc" isoforms with additional ligand-binding properties. For instance, FGFR2IIIb binds FGF7 and FGF10, but not FGF2, whereas the FGFR2IIIc isoform binds FGF2 and FGF18, but not FGF7 and FGF10 (see Ref. [12] for further details about the ligand-binding properties of the different FGFRs). Interestingly, FGFR1-3IIIb and FGFR1-3IIIc isoforms often display differential expression in epithelial and mesenchymal tissue, respectively [13].

FGFRs interact with HSPGs via the D2 domain. The formation of a $2: 2: 2 \mathrm{HSPG} / \mathrm{FGF} / \mathrm{FGFR}$ ternary complex [14] causes receptor dimerization with conformational shift in receptor structure that leads to trans-phosphorylation of multiple residues in the intracellular TK domain. Receptor phosphorylation activates multiple signal transduction pathways that generate distinct cellular responses. As summarized in Fig. 1, major substrates of FGFR TK are the intracellular specific adaptor protein FGFR-substrate-2 (FRS2) and phospholipase-C $\gamma$ (PLC $\gamma$ ) [15]. Activated FRS2 allows the recruitment of the adaptor protein GRB2 that in turn recruits SOS or GAB1 to the signal complex. The recruitment of SOS activates RAS and the downstream RAF/mitogen-activated protein kinase (MAPK) pathway. The downstream effect of this pathway is mainly cell proliferation, even though cell differentiation or cell cycle arrest can also be induced depending on the different cellular context. The recruitment of GAB1 causes the PI3K-mediated activation of the AKT antiapoptotic pathway. PLC $\gamma$ leads to the activation of protein kinase $\mathrm{C}$ (PKC) that sustains MAPK and AKT pathways and plays a role in cell migration. Other pathways may be activated in different cell subtypes, including p38 MAPK, JAK-STAT and RSK2 [16].

Several extracellular and intracellular mechanisms have been described able to regulate/attenuate FGFR signalling at different levels. FGFRs are internalized upon receptor activation [17], inducing receptor degradation or recycling. Relevant to this point, N-glycosylation of the receptor affects the assembly of the FGF/FGFR1/HSPG complex [18] and internalization of FGFR2 [19]. At intracellular level, MAPK signalling may phosphorylate threonine residues on FRS2, inhibiting the recruitment of GRB2 [20]. Sprouty proteins are negative modulators that compete for GRB2 binding by preventing RAS activation or directly binding RAF and disrupting MAPK signalling [21]. In addition, FGFs can induce the activation of phosphatases, including SEF and MAPK-phosphatase 3 (MKP3). SEF interacts directly with FGFRs, thus preventing their activation, whereas both enzymes can dephosphorylate and inactivate $\mathrm{ERK}_{1 / 2}$ [22].

Different molecules can act as cell surface co-receptors for FGFs (Fig. 2 ). As already mentioned, HSPGs are required for a productive FGF/FGFR interaction that enables FGFR signalling [23]. For this reason, structural modifications of the HS chains deeply affect FGFR signalling and can be responsible for its fine-tuning. As an exception, hormone-like FGFs have reduced affinity for HSPGs and their activity depends on the presence of Klotho proteins as co-receptors. Cell surface $\beta$-Klotho and $\alpha$-Klotho are co-factors for FGF19/21 and FGF23, respectively, and convert FGFRs into high affinity receptors for endocrine FGFs, limiting nonspecific/off-target signalling. The cell membrane ganglioside GM1 acts as a FGF co-receptor by interacting with FGF2 and promoting its biological activity in endothelial cells [24]. In addition, $\alpha v \beta 3$ integrin promotes FGF-mediated endothelial cell proliferation, motility, and FGFR1 recruitment [25], thus contributing to the cross-talk between FGFR and integrin signalling [26]. Neural cell adhesion molecule (NCAM), neuronal cadherin ( $\mathrm{N}$-cadherin) and L1 can activate FGFR1-2 


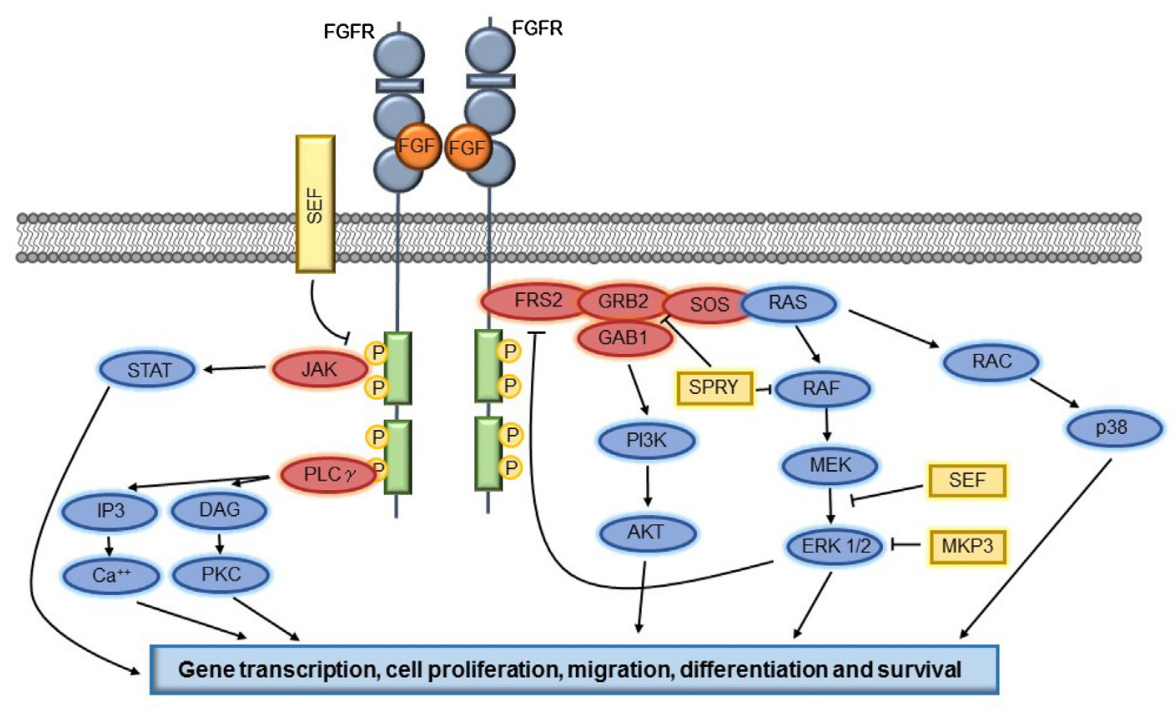

Fig. 1. FGFR signalling pathways.

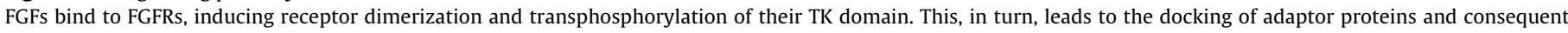

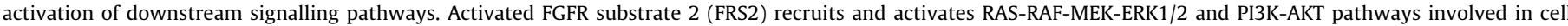

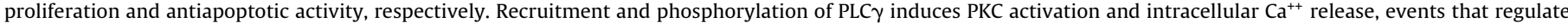
cell motility. The negative regulators MKP3 and SPRY can modulate FGFR signalling whereas SEF may also interfere with ligand binding.

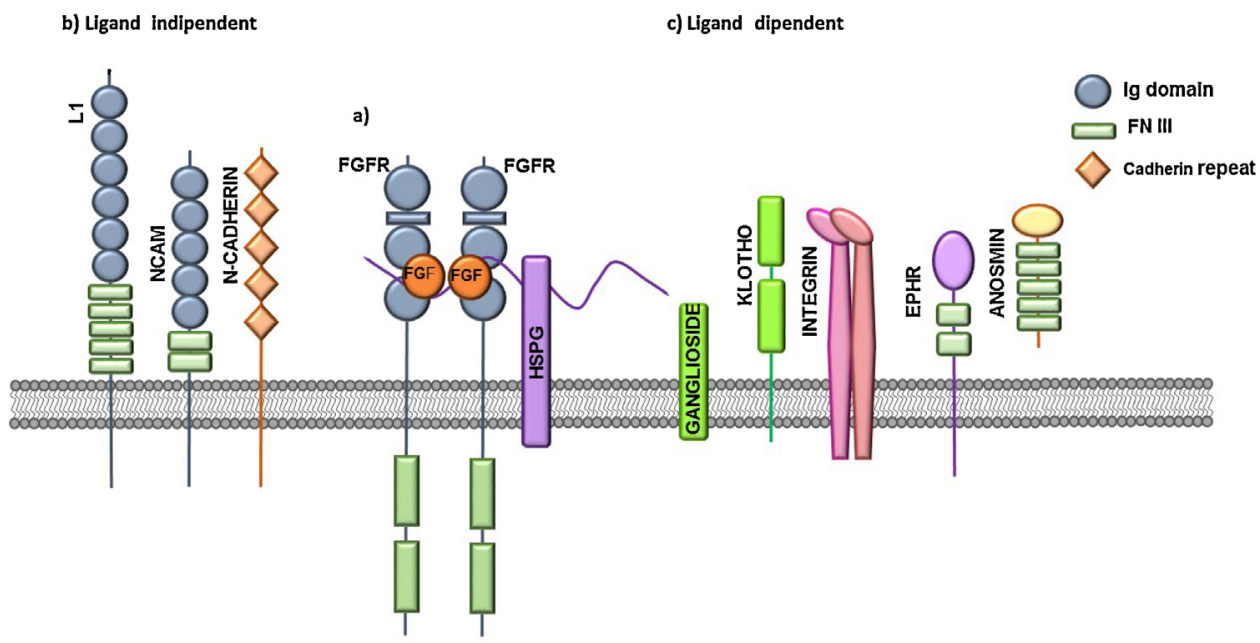

Fig. 2. FGFR co-receptors.

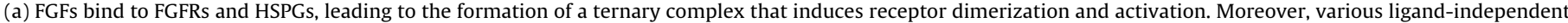
(b) and ligand-dependent (c) cell-surface proteins and glycolipids may act as FGFR co-receptors.

in the absence of canonical FGFR ligands and this interaction is mediated by the acid box motif in the linker region between the D1 and D2 Ig-like loops of the receptor [27]. Therefore, N-CAM and N-cadherin act as a nonconventional FGFR1 ligand, promote receptor stabilization and exert a peculiar control on FGFR intracellular trafficking [28]. Extracellular matrix-associated glycoprotein anosmin-1 binds FGFR1 in a HS-dependent manner, modulating FGFR signalling during development [29]. Finally, EphA4 has been identified as a binding partner for FGFRs. The interaction occurs between the juxtamembrane region of FGFR and the cytoplasmic domain of EphA4 and leads to enhanced level of MAPK signalling and stimulation of cell proliferation [30].

\section{The FGF/FGFR system in endothelial cells}

Angiogenesis is an essential process for tumor growth and progression, since the large-scale growth of a tumor ultimately requires an adequate blood supply [31]. Indeed, once a tumor lesion exceeds a few millimeters in diameter, hypoxia and nutrient deprivation trigger an 'angiogenic switch' to allow the tumor to progress [32]. In 1980s, the purification to homogeneity of tumor angiogenic proteins led to the first identification of the two heparin-binding angiogenic growth factors FGF1 and FGF2 [33,34]. At present, FGF1 and FGF2 still represent the prototypical and best studied members of the canonical FGF subfamily. In vivo they exert a potent pro-angiogenic effect in different experimental models, including the chick embryo chorioallantoic membrane (CAM) [35], rabbit/mouse cornea [36] and murine subcutaneous Matrigel plug [37] assays.

Besides FGF1 and FGF2, only scattered pieces of information indicate that other FGFs show clear pro-angiogenic properties (like FGF4 and FGF8) whereas few or controversial data have been reported for the remaining members of the FGF family (see Ref. [38] for an extensive review). Interestingly, the apparent redundancy of the FGF family may lead to complementary/compensatory actions, 


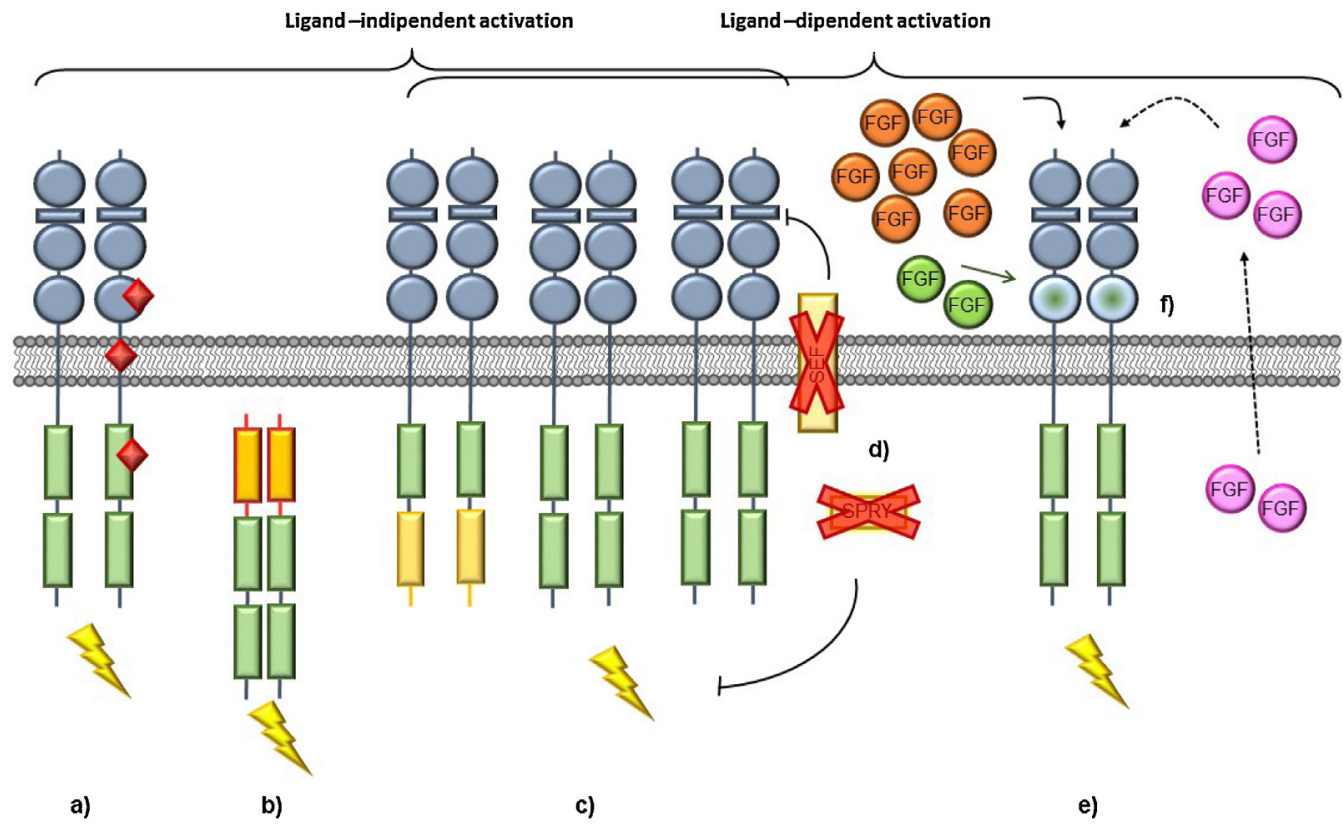

Fig. 3. Deregulation of the FGF/FGFR system in cancer.

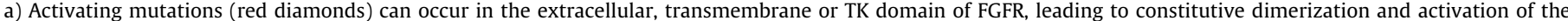

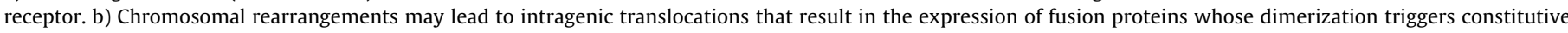

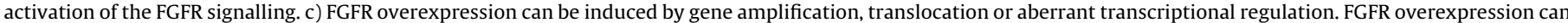

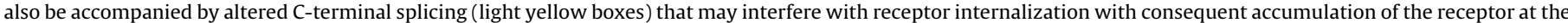

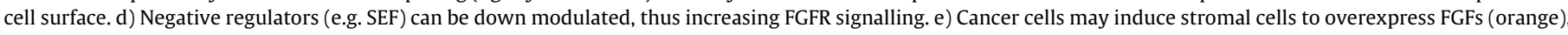

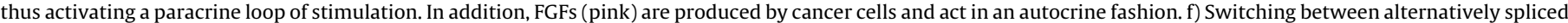
receptor isoforms may induce imbalanced FGFR signalling with altered specificity for FGF ligands (green).

making difficult the identification of the biological significance of the various FGFs by the gene knockout approach. For instance, FGF2 knockout and FGF1/FGF2 double-knockout mice develop normally with only mild phenotypic defects in their wound healing capacity associated with FGF1/FGF2 deletion [39].

Of note, human umbilical vascular endothelial (HUVE) cells express several canonical FGFs (including FGF1, FGF2, FGF5, FGF7, FGF8, FGF16, FGF18) and two FGF homologous factors (FGF11 and FGF12) [40], thus suggesting that FGFs may also exert autocrine functions in endothelium.

Even though a comprehensive study is still missing, endothelial cells express different members of the FGFR family, FGFR1IIIc being the most represented receptor while FGFR2-IIIc and FGFR3IIIc are expressed at lower levels [40]. Experiments performed on FGFR1 and FGFR2 null mice in both endothelial and hematopoietic cells indicate that these receptors are not required for vascular homeostasis or physiological functions. However, FGFR signalling in endothelial cells plays a pivotal role in tissue repair and neovascularization following injury, pointing to endothelial cell FGFRs as a target for the therapy of diseases characterized by an aberrant vascular proliferation [41].

The formation of HSPG/FGF/FGFR ternary complexes causes receptor dimerization and trans-phosphorylation of multiple residues in the intracellular FGFR TK domain. This leads to the activation of a complex "pro-angiogenic phenotype" in endothelial cells that recapitulates several aspects of the in vivo angiogenesis process, including modulation of endothelial cell proliferation, migration, protease production, integrin and cadherin receptor expression, and intercellular gap-junction communication (summarized in Ref. [42]). For instance, FGF1, FGF2, FGF4, FGF7 and FGF8b bind and activate FGFR1 or FGFR2, stimulating endothelial cell proliferation [43]. In addition, FGFs can modulate extracellular matrix degradation, as reported for the capacity of FGF1 and FGF2 to induce the secretion of MMP1 and MMP3 in endothelial cells [44] and the capacity of FGF2 to stimulate the shedding of endothelial membrane vesicles containing MMP1, MMP9 and metalloprotease inhibitors TIMP-1 and TIMP-2 [45]. Also, various studies demonstrate that FGFs promote endothelial cell migration, as shown by the ability of FGF1, FGF2, FGF7, FGF16 and FGF18 to induce a chemotactic response in endothelium $[43,46]$.

\section{Deregulation of the FGF/FGFR system in cancer cells}

An aberrant regulation of the FGF/FGFR system may occur in human tumors, leading to the deregulated activation of liganddependent or ligand-independent FGFR signalling. As summarized in Fig. 3, this may represent the consequence of activating FGFR mutations that occur in the extracellular, transmembrane or TK domain of the receptor; chromosomal rearrangements that result in the expression of FGFR signalling fusion proteins; FGFR overexpression induced by gene amplification, translocation, aberrant transcriptional regulation or down-modulation of negative regulators; FGF overexpression by stromal and/or tumor cell, leading to the activation of autocrine/paracrine loops of stimulation. Clearly, while FGFR mutations are anticipated to impact mainly the tumor cell behavior, FGF overexpression by tumor cells may exert both autocrine and paracrine effects, thus contributing to the epithelial/stroma cross-talk that occurs in the tumor microenvironment. In addition, depending on the molecular mechanism responsible for the ligand-dependent or ligand-independent deregulation of FGFR signaling in a given neoplasm, different approaches can be envisaged aimed at targeting the FGF/FGFR system at the extracellular or intracellular level (see below).

\subsection{Activating mutations}

The screening from 210 different human cancers of 1000 somatic mutations in the coding exons of 518 protein kinase genes 
Table 1

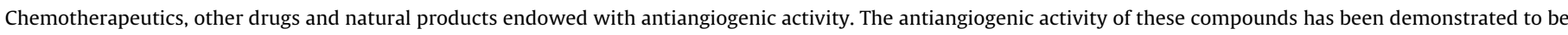

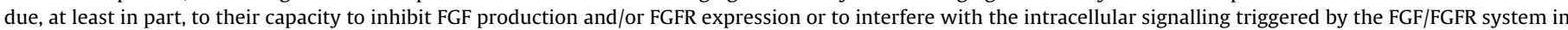
endothelial cells (see references for further details).

\begin{tabular}{|c|c|c|}
\hline Chemotherapeutics & Main tumor target(s) (FDA approved) & Ref \\
\hline 6-methylmercaptopurine-riboside & acute lymphatic leukemia & [159] \\
\hline topoisomerase-I inhibitor topotecan & small cell lung cancer, metastatic ovarian cancer & [160] \\
\hline medroxyprogesterone-acetate & endometrial cancer, breast cancer in post menopausal women & [161] \\
\hline Tamoxifen & breast cancer in post menopausal women & {$[162]$} \\
\hline Thalidomide & multiple myeloma & [163] \\
\hline quinazoline-derived $\alpha 1$-adrenoreceptor antagonist doxazosin & prostate cancer & {$[164]$} \\
\hline 6-thioguanine & acute myelogenous leukemia & [165] \\
\hline Atiprimod & relapsed acute lymphoblasticand myeloid leukemias & [166] \\
\hline etoposide & small cell lung cancer, testicular cancer & [167] \\
\hline combination of tegafur and uracil (UFT) & advanced colorectal cancer, various cancer $^{\mathrm{a}}$ & [168] \\
\hline Other drugs & Original therapeutic indication & \\
\hline Tranilast & anti-allergic drug & [169] \\
\hline Spironolactone & heart failure & {$[170]$} \\
\hline Zoledronic acid & various skeletal complications & {$[171]$} \\
\hline Cidofovir & cytomegalovirus retinitis in AIDS patients & {$[172]$} \\
\hline Indomethacin & nonsteroidal anti-inflammatory drugs & [173] \\
\hline Celecoxib & & {$[174]$} \\
\hline Cerivastatin & hypercholesterolemia & [175] \\
\hline Ticlopidine (derivatives) & platelet antiaggregating agent & [176] \\
\hline Triamcinolone acetonide & intraocular disorders & {$[177]$} \\
\hline HyPE (secretory phospholipase-A2 inhibitor) & asthma & {$[178]$} \\
\hline Natural products & Source & \\
\hline curcumin & Curcuma longa & [179] \\
\hline epigallocatechin-3-gallate & green tea & {$[180]$} \\
\hline Gleditsia sinensis & fruit extract & {$[181]$} \\
\hline 1,2,3,4,6-penta-O-galloyl-beta-D-glucose & Galla Rhois & [182] \\
\hline 4-O-methylgallic acid & dietary legume Canavalia gladiate & [183] \\
\hline resveratrol & grapes and wine & [184] \\
\hline glyceollins & soybean & [185] \\
\hline alliin & garlic & [186] \\
\hline stilbene glycosides & Boswellia papyriferai & [187] \\
\hline salvicine & Salvia prionitis Hance & [188] \\
\hline polymethoxyflavonoid nobiletin & citrus & [189] \\
\hline aplidine & marine-derived depsipeptide & [190] \\
\hline philinopside $\mathrm{A}$, & sea cucumber Pentacta quadrangulari & [191] \\
\hline psammaplin A & marine sponge & [192] \\
\hline carrageenan & edible seaweeds & [193] \\
\hline carotenoids & marine algae & [194] \\
\hline epoxydocosapentaenoic acids (EDPs) & omega-3 dietary fatty acids (fish oil) & [195] \\
\hline 1-O-alkylglycerols & fish liver oils & [196] \\
\hline Neovastat (AE-941) & cartilage & [197] \\
\hline
\end{tabular}

a Approved in UK and Japan.

highlighted various components of the FGF signalling pathways as the most commonly mutated genes in the subset of nonsynonymous mutations [47]. For instance, $\sim 50 \%$ of bladder cancers have somatic mutations in the FGFR3-coding sequence [48], more than half of the mutations occurring at a single position (S249C) in the extracellular domain of the receptor. This mutation leads to the formation of an aberrant intermolecular cysteine bridge that results in ligand-independent constitutive dimerization and activation of the receptor [49]. FGFR3 mutations have also been identified in many other cancer types, including cervical cancers [50], multiple myeloma (MM) [51,52], prostate cancers [53], spermatocytic seminomas [54] and oral squamous carcinomas [55]. Other mutations located in the TK domain can change the FGFR conformation, leading to a constitutive ligand-independent receptor activation, as observed for FGFR4 in the childhood rhabdomyosarcoma [56].

At variance with FGFR genes, FGF mutations are rare in human cancers and their impact on cancer biology is unclear. Indeed, to the best of our knowledge, somatic mutations have been described only for FGF9 in colorectal and endometrial cancers [57]. They are predicted to result in loss-of-function and it is not known whether these mutations participate in tumor formation.

\subsection{Gene overexpression and amplification}

Elevated FGFR levels can be observed in human cancers as the consequence of deregulated gene transcription or amplification. Also in this case, this will lead to the activation of FGFR signalling in a ligand-independent manner. At variance with the activation of FGFR3 by somatic mutations, FGFR3 gene amplification has been rarely described in cancer [58]. In contrast, both FGFR1 and FGFR2 amplifications are more commonly found. For instance, amplification of the chromosomal region 8p11-12, the genomic location of FGFR1, is one of the most common focal amplifications in breast cancer [59]. It occurs in approximately $10 \%$ of breast tumors and predominantly in estrogen receptor (ER)-positive cancers [59]. Recent studies have demonstrated focal FGFR1 amplification in non-small cell lung carcinoma cells in 3\% of lung adenocarcinomas and $21 \%$ of squamous cell carcinomas [60,61]. FGFR1 amplifications have been observed also in oral squamous carcinomas [62] and are found at a low incidence in ovarian cancer [63], bladder cancer [58] and rhabodomyosarcoma [64]. As to FGFR2, approximately $10 \%$ of gastric cancers show FGFR2 amplification, which is associated with poor prognosis in diffuse-type cancers [65]. In addition, FGFR2 amplification occurs in approximately $2 \%$ of breast cancers and breast cancer SUM52PE and MFM-223 cell lines 
Table 2

Natural FGF2-trap molecules.

\begin{tabular}{l}
\hline FGF2-trap molecule ${ }^{\mathrm{a}}$ \\
\hline TSP-1 \\
fibstatin (fibronectin fragment) \\
gangliosides \\
PDGF \\
$\alpha_{2}$-macroglobulin \\
PTX3 \\
heparin, free HSPGs \\
CXCL13 \\
CXCL4 \\
soluble form of the extracellular portion of FGFR1
\end{tabular}

a See $[114,198]$ and references therein.

are sensitive to inhibition of the FGF/FGFR system [66]. Of note, breast and gastric cancer cell lines harbouring FGFR 2 amplifications predominantly express the IIIb isoform of the receptor. Thus, neutralizing FGFR2-IIIb-specific antibodies (like the GP369 antibody) can suppress ligand-induced phosphorylation of the receptor and downstream signalling, leading to the inhibition of tumor cell proliferation in vitro and in vivo [66].

\subsection{Chromosomal translocations}

Chromosomal translocations can lead to the expression of fusion proteins with potent oncogenic function. Some of the strongest evidences linking FGFR signalling to oncogenesis derive from the study of haematological malignancies in which FGFR translocations have been observed. Several FGFR intragenic translocations have been identified that typically result in a fusion protein comprising the $\mathrm{N}$ terminus of a transcription factor fused to the TK domain of FGFR1-3 (77), leading to the constitutive dimerization of the fusion protein and TK activation. For example, ZNF198-FGFR1 and BCR-FGFR1 fusion proteins have been found in EMS (8p11 myeloproliferative syndrome) [67] and fusion of ETV6 to FGFR3 has been reported in peripheral T-cell lymphoma with a $\mathrm{t}(4 ; 12)(\mathrm{p} 16 ; \mathrm{p} 13)$ chromosomal translocation [68]. A different translocation has been found in MM in which $15 \%$ of tumors harbor a $\mathrm{t}(4 ; 14)$ translocation that links FGFR3 at 4p16.3 to the immunoglobulin heavy chain IGH locus at $14 q 32$ [52]. This translocation is intergenic, with the breakpoints occurring $\sim 70 \mathrm{~kb}$ upstream of FGFR3, and brings FGFR3 under the control of the highly active IGH promoter. The ultimate effect of this translocation is the overexpression of FGFR3 out of context, that may result in aberrant hypersensitivity to ligands [69] or to ligand-independent signalling. The $\mathrm{t}(4 ; 14)$ translocation is associated with poor prognosis in MM, FGFR3 representing an attractive therapeutic target for this tumor. Interestingly, oncogenic FGFR3 gene fusions have been identified also in bladder cancer in which genomic FGFR3 translocations involve two different fusion partners that generate constitutively activated FGFR3 kinases [70].

\subsection{Aberrant autocrine and paracrine ligand signalling}

Most of the genomic aberrations discussed above lead to constitutive receptor activation and ligand-independent signalling. On the other hand, also the activation of a ligand-dependent signalling may play an important role in the pathogenesis of cancer. This may occur via the activation of autocrine mechanisms of stimulation due to FGF production by cancer cells or may represent the consequence of the paracrine activity exerted on cancer cells by FGF(s) produced by the surrounding stroma. In this context, several murine models have shown that ectopic FGF expression can promote cancer and that FGF overexpression by epithelial cells may induce carcinogenesis through an autocrine loop of stimulation. Examples include: FGF8 expression driven by the MMTV-LTR promoter that causes the occurrence of lobular-type mammary adenocarcinomas in mice at 1 year of age [71]; FGF8 expression in prostate epithelium that initiates prostatic intraepithelial neoplasia and prostatic cancer when occurring in a Pten haploinsufficient background [72]; the conditional expression of FGF10 in lung epithelium that induces pulmonary tumors [73].

The first strong evidence for a role of autocrine FGF signalling in driving human tumorigenesis comes from seminal studies on melanomas that express high levels of FGFR1 and FGF2 [74]. Since then, elevated levels of different members of the FGF family have been found in numerous human cancers [38]. Amplification of FGF1, resulting in increased FGF1 expression, has been frequently observed in ovarian cancer and is associated with poor survival [75]. An aberrant autocrine FGF2/FGFR1-IIIc feedback loop of stimulation has been found in human non-small-cell lung cancer cell lines resistant to the epidermal growth factor receptor (EGFR) antagonist gefitinib [76]. Similar results were obtained for human head and neck squamous carcinoma cell lines. Indeed, FGF2 and FGFR coexpression frequently occurs in these cells, leading to an autocrine loop of stimulation that may involve also EGFR activation [77]. Several FGFs, including FGF1, FGF2, FGF5, FGF6, FGF7, FGF8, FGF9, FGF10, FGF17, FGF18 and FGF19 are upregulated in human prostate cancer [38] and murine studies have demonstrated the complex FGF/FGFR-dependent interplay between the epithelial and mesenchymal compartments in these tumors [78].

Besides the aberrant activation of autocrine loops of stimulation, paracrine FGF production might also contribute to tumorigenesis. Increased plasma levels of FGF2 and other FGFs are found in multiple cancer types [79]. This partly reflects the increased release of FGFs as tumors invade and degrade the extracellular matrix [80], free FGF molecules acting in turn as paracrine factors. Tumor cells may also induce FGF2 release from the stromal inflammatory infiltrate [81] that may promote tumor survival via a paracrine loop of stimulation and trigger a pro-angiogenic response. Neovascularization can be further augmented by an autocrine production of angiogenic FGF2 by endothelial cells [81].

\section{The role of the FGF/FGFR system in tumor/stroma cross-talk}

Tumors are heterogeneous cellular entities composed of cancer cells and cells of the microenvironment in which they reside [82]. Similar to stromal cells in normal epithelial tissues, stromal cells forming the tumor microenvironment include inflammatory cells (lymphocytes, macrophages and mast cells), fibroblasts and vascular components. The genetic basis of carcinogenesis involves the acquisition of multiple genetic mutations in epithelial cells [83]. Then, tumor cells transform the surrounding stroma into a so-called "activated stroma" that, in turn, can strongly influence/support tumorigenesis and tumor progression [82]. Thus, a reciprocal dynamic interaction occurs between tumor cells and activated stromal cells during cancer initiation and progression. This tumor-host communication interface mediates the proliferation of tumor cells at the primary site, the process of tumor angiogenesis, the migration and survival of cancer cells in the vasculature, and the growth of metastatic lesions at secondary sites through the autocrine/paracrine secretion of ECM proteins and growth factors [84]. Also, emerging evidences emphasize the ability of stromal cells to modulate tumor cell resistance or sensitization to different classes of therapeutics, depending on the specific microenvironmental context [85]. Thus, the tumor microenvironment has become the focus of intense research, with the understanding that the alterations that occur in the tumor stroma might provide important prognostic hints, can affect the 
evaluation and selection of candidate drugs, and the generation of new therapeutic targets for various cancers.

As stated above, the FGF/FGFR system may play a critical role during carcinogenesis by regulating the cross-talk between epithelial and stromal compartments. Enhanced FGFR signalling may have myriad effects on tumor biology, including promotion of proliferation, resistance to cell death, augmented motility and invasiveness, increased neovascularization, enhanced metastatic spreading and resistance to chemotherapy and radiation. Several studies have highlighted the importance of FGF/FGFR signalling in mediating epithelial-stromal interactions during prostate carcinogenesis $[86,87]$. For instance, overexpression of FGF10 in prostatic stroma by lentiviral delivery results in epithelial hyperproliferation that correlates with upregulation of androgen receptor expression [78]. Furthermore, the combination of FGF10 stromal overexpression with the epithelial expression of a constitutively activated form of Akt (myristoylated Akt1) results in cooperative effects on prostate tumorigenesis [78]. However, the translational significance of these murine models for human cancer remains unclear since FGF10 has not been found to be significantly expressed in human prostate cancer [88]. Nonetheless, it is conceivable that other members of the FGF family with receptor-binding specificities similar to FGF10 may be relevant in human prostate cancer, including FGF7 and FGF22. Also, activation of prostate tumor cell growth through androgenindependent stromal growth factor signals, such as FGF7, may occur under conditions of androgen deprivation [89]. These data may help to develop new therapeutic strategies to target the prostate tumor stroma under androgen-manipulated conditions. Interestingly, a recent study has demonstrated that downregulation of the micro-RNAs miR-15 and miR-16 in prostate cancer-associated fibroblasts (CAFs) promotes tumor growth and progression through the reduced post-transcriptional repression of FGF2 and of its receptor FGFR1 [90]. Moreover, reconstitution of miR-15 and miR-16 significantly impaired the tumor-supportive capability of stromal cells in vitro and in vivo, thus enforcing the therapeutic concept aimed at reconstituting the expression of these micro-RNAs in advanced prostate cancer [90].

Besides its autocrine role in human melanoma, FGF2 may exert also paracrine functions in stroma formation during the progression of this tumor. Indeed, FGF2 appears to act on fibroblasts and endothelial cells in order to modulate the tumor microenvironment, thus favoring melanoma growth, neovascularization, invasion, and metastasis [91].

A recent study has identified FGF4 as a growth-promoting and radioprotective factor produced by CAFs in cervical cancer, leading to the activation of a tumor cell/CAF cross-talk that may confer a survival signal to overcome cell death in irradiated cervical cancer cells [92]. In addition, FGF2, FGF7 and FGF10 are implicated as autocrine and paracrine mediators of tumor-stroma interactions in pancreatic ductal adenocarcinomas [93]. In these tumors, mast cells, macrophages, and tumor cells overexpress VEGF-A, VEGF-C, and FGF2 and this was highly correlated to intratumor microvessel density [94].

Interestingly, the FGFR inhibitor PD173074 abrogates the rescue effect exerted by fibroblast supernatant on the cytostatic effects exerted by the TK inhibitor lapatinib on esophageal squamous-cell carcinoma cells [95]. These findings suggest a role for FGF/FGFR signalling in tumor drug resistance induced by stromal fibroblasts and suggest that a combination therapy with lapatinib and a FGF/FGFR inhibitor might be effective in overcoming therapeutic resistance in esophageal squamous-cell carcinoma.

FGF2 is considered a potent angiogenic cytokine in MM. Both MM-derived cell lines and tumor cells isolated from the bone marrow of MM patients express and secrete FGF2, cell sorting studies indicating tumor cells as the predominant source of FGF2 in MM bone marrow [96,97]. Besides its pro-angiogenic functions, FGF2 plays also an important role in mediating tumor-stromal cell interactions in MM [98]. Indeed, bone marrow stromal cells (BMSCs) from MM patients express FGFR1-4 and stimulation of BMSCs with FGF2 induces a time- and dose-dependent increase of interleukin6 (IL-6), a potent growth and survival factor for MM cells [99]. Accordingly, IL-6 secretion is fully abrogated by anti-FGF2 antibodies, while stimulation with IL-6 enhances FGF2 expression and secretion by MM cell lines as well as by primary MM tumor cells, an effect inhibited by anti-IL-6 antibodies. These findings demonstrate a paracrine interaction between myeloma and bone marrow stromal cells triggered by the mutual stimulation of FGF2 and IL-6.

Finally, FGFs may activate a pro-inflammatory phenotype in endothelium [100], indicating that the FGF/FGFR system may influence also the immune/infiltrate component of tumor milieu.

All these considerations highlight the FGF/FGFR system as a critical player in tumor/stroma cross-talk in several cancer types. Thus, blocking the FGF/FGFR system may represent a "two-compartment" antitumor/antiangiogenic approach in cancer therapy.

\section{Inhibition of the FGF/FGFR system: therapeutic approaches}

Various approaches can be envisaged to neutralize the aberrant activation of the FGF/FGFR system that occurs in cancer, with its consequent effects on both parenchymal and stromal tumor compartments. In particular, we can distinguish between the possibility to prevent/modulate the FGF-FGFR interaction that occurs at the extracellular level or to impair the intracellular signal transduction pathways triggered by the deregulated activation of the receptor.

\subsection{Inhibition of FGF/FGFR system at the extracellular level}

\subsubsection{Inhibition of the expression of FGF/FGFR/FGFR co-receptors}

A first approach in order to prevent the aberrant activation of the FGF/FGFR system is represented by the possibility to suppress the production of FGFs. To this regard, the capacity to inhibit the production of angiogenic growth factors is a common feature of different chemotherapeutics (like taxane [101] and docetaxel [102]) that downregulate FGF expression by exerting their antiblastic effect on FGF-producing tumor cells (Table 1). In addition, an interesting antiangiogenic and antitumor activity is exerted in vivo by antisense FGF2 oligonucleotides that block FGF production by both tumor and endothelial cells [74,103], as well as by various inhibitors of second messengers involved in FGF expression (i.e. PKC, JAK, PI-3 K, c-jun, ERK, JNK, STAT1 and STAT3) [104]. Finally, natural products, including genistein, fumagillin, curcumin, salvicine and the green tea component epigallocatechin-3-gallate (Table 1), oxidized low-density lipoproteins [105] and some endogenous cytokines [106] have been reported to negatively regulate the expression of FGFs.

Besides FGFs, also the expression of FGFRs and their co-receptors can be suppressed for therapeutic purposes. To this regard, IFN$\gamma$ and IL-1 can down-regulate FGFR expression [107]. In addition, transfection with FGFR1 antisense cDNAs, as well as reduction of FGFR2 expression by the synthetic retinoid fenretinide, impaired FGF2-dependent proliferation and migration of endothelial cells in vitro [108] and tumor angiogenesis in vivo [109].

Examples of how modulation of cell surface FGFR co-receptors can be exploited as an antiangiogenic/antitumor strategy are represented by antithrombin, that inhibits endothelial cell proliferation by down-regulating the surface expression of perlecan [110], and specific inhibitors of the synthesis of complex gangliosides, including fumonisin $\mathrm{B}_{1}$, D-threo1-phenyl-2-decanoylamino-3-morpholino-1-propanol, and 
Table 3

Inhibitors of FGF/FGFR-mediated intracellular signalling and biological activity.

\begin{tabular}{|c|c|}
\hline Targeted second messenger & Inhibitor $^{\mathrm{a}}$ \\
\hline Pan-TK & $\begin{array}{l}\text { TKI258, tyrphostin } 23 \text {, genistein, herbimycin A, axitinib, brivanib, cabozantinib, dovotinib, nintedanib, oratinib, } \\
\text { pazopamib, ponatinib, regorafenib, sorafenib, sunitinib and vandetanib }\end{array}$ \\
\hline FGFR TK & $\begin{array}{l}\text { SU5416, SU6668, SU5402, Z24, PD173074, SSR128129E, AZD4547, BGJ398, LY287445, CP-547,632, dominant negative } \\
\text { mutant overexpression }\end{array}$ \\
\hline FAK & dominant negative mutant overexpression \\
\hline ERK $_{1 / 2}$ & PD098059, U0126, apigenin, dominant negative mutant overexpression \\
\hline P38 & SB203580 \\
\hline PI3K & LY294002, apigenin, dominant negative mutant overexpression \\
\hline PKC & Bis I, G06983, GFX, chelerythrine, H7, NSC 639366, calphostin C, dominant negative mutant overexpression \\
\hline Rac & dominant negative mutant overexpression \\
\hline Ras & manumycin A, FTS, FPT inhibitor III, dominant negative mutant overexpression \\
\hline Raf & dominant negative mutant overexpression \\
\hline c-Src & PP1, PP2, dominant negative mutant overexpression \\
\hline $\mathrm{SH} 2$ & dominant negative mutant overexpression \\
\hline MEK & dominant negative mutant overexpression \\
\hline PLC- $\gamma$ PLC- $\alpha$ & aristolochic acid, ONO-RS-082 \\
\hline AKT & ML-9, dominant negative mutant overexpression \\
\hline NF-kB & dominant negative mutant overexpression \\
\hline c-Fyn & dominant negative mutant overexpression \\
\hline c-jun & antisense oligonucleotide \\
\hline PAK & dominant negative mutant overexpression \\
\hline JNK & dominant negative mutant overexpression \\
\hline $\mathrm{P}^{\mathrm{S}} \mathrm{S}^{\mathrm{S}} \mathrm{K}$ & Rapamycin \\
\hline RhoA & $\mathrm{C} 3$ \\
\hline c-FES & dominant negative mutant overexpression \\
\hline Grb2 & Grb2-Src homology 2 domain binding antagonist \\
\hline cAMP & Forskolin, 8-bromo AMPc \\
\hline Ets-1 & dominant negative mutant overexpression \\
\hline Egr-1 & neutralizing single-stranded DNA \\
\hline $\mathrm{Ca}^{++}$influx & CAI \\
\hline G-proteins & pertussis toxin \\
\hline
\end{tabular}

a See $[146,147]$ and references therein.

D-1-threo-1-phenyl-2-hexadecanoylamino-3-pyrrolidino-1propanol, that affect endothelial cell proliferation triggered by FGF2 [111]. HSPGs can be removed from the cell surface by heparinase treatment that abolishes FGF2-dependent cellular responses [108]. Alternatively, HSPGs can be modified to inhibit their interaction with FGFs, as in the case of sodium chlorate treatment that induces the preferential reduction of trisulfated disaccharide units, thus preventing FGF2 binding, internalization and mitogenic activity [112].

\subsubsection{Preventing $F G F / F G F R / c o$-receptor interactions}

One of the most exploited approaches for the design of inhibitors of the FGF/FGFR system is based on the production of neutralizing anti-FGF antibodies $[103,113]$ and the search for natural and synthetic FGF binders that sequester the growth factor in the extracellular compartment, thus acting as FGF traps [114,115]. Natural FGF binders (Table 2) have been identified in the ECM and body fluids. Among them, thrombospondin-1 (TSP-1), long pentraxin-3 (PTX3), heparin $[87,91,116]$ and soluble decoy FGFRs [117] have been exploited for therapeutic purposes. For instance, molecular modeling and protein-protein interaction studies were used to map the amino acid residues involved in TSP-1/FGF2 and PTX3/FGF2 binding. The information was translated into pharmacophore models for the screening of small molecule databases. This approach led to identification and characterization of TSP1 peptidomimetics [116] and PTX3-derived peptides and small molecules [118-120] acting as FGF traps and endowed with antiangiogenic and antitumor properties.

As a component of body fluids, heparin is a negatively charged glycosaminoglycan released in the blood stream during inflammation. It binds almost all the members of the FGF family and acts as an antagonist of the FGF/FGFR system. Unfortunately, its use in the clinics as FGF inhibitor is hindered by its potent anticoagulant activity. This has led to the search and identification of heparin-like polyanionic molecules acting as FGF traps but with reduced anticoagulant activity. They include, among others, polysulfated/polysulfonated compounds and biotechnological heparins (see Ref. [121] for a comprehensive review about this point). Since heparin binds a variety of angiogenic/mitogenic growth factors besides FGFs [122], heparin-like drugs might have the advantage to sequester various growth factors simultaneously, acting as "multitarget" inhibitors [123]. On the other hand, a too broad binding capacity may lead heparin-like compounds to affect multiple biological processes with consequent undesired side effects and/or toxicity.

Finally, prototypic FGF traps can be represented by soluble forms of the extracellular portion of FGFRs that function as decoy molecules able to bind and sequester FGFs, thus preventing their interaction with the full length transmembrane signalling receptor. To date, the most promising molecule is represented by FP-1039, a soluble FGFR1(IIIc)-Fc fusion protein that binds tightly and inhibits almost all FGFs. This molecule has entered the clinical trial evaluation process [124].

The identification of functional FGF domains responsible for their binding to the different cognate receptors has been exploited for the production of synthetic "masking" peptides. As an example, the peptide comprising the amino acid sequence FGF2(112-155) impaired the interaction of FGF2 with FGFR1 [125] and similar peptides were successfully employed to specifically deliver antiblastic drugs to FGFR-overexpressing tumor cells [126]. In addition, vaccination against FGFR1 showed antitumor activity in vivo [127] and anti-FGFR neutralizing antibodies blocked FGF2-mediated angiogenesis in vivo [113,128-130].

As stated above, FGFR co-receptors deeply influence the ligand/receptor recognition. Thus, interesting approaches have been developed to affect their activity. For instance, FGF2 contains two DGR sequences that are the inverse of the integrin-recognition sequence RGD present in several cell-adhesive proteins. Con- 
sistently, both RGD-containing peptides and DGR-containing FGF2-derived peptides inhibit $\alpha_{\mathrm{v} \beta 3}$ integrin-mediated endothelial cell adhesion to FGF2 and cell proliferation [131,132]. Accordingly, RGD-peptidomimetics inhibit FGF2-dependent neovascularization and tumorigenesis [133]. Relevant to this point, monoclonal anti$\alpha_{\mathrm{v} \beta 3}$ antibodies prevent FGF2 $/ \alpha_{\mathrm{v} \beta 3}$ interaction thus impairing endothelial cell adhesion, proliferation and protease upregulation in vitro [132] and FGF2-mediated angiogenesis in vivo [134]. A similar mechanism of action may be shared by disintegrins, a class of naturally occurring integrin antagonists that have been demonstrated to inhibit different aspects of FGF2 biology [135].

Besides integrins, also HSPGs can be masked to obtain an antiangiogenic effect. The FGF2-mimicking synthetic peptide F2A4-K-NS binds and masks HSPGs to FGF2 [136]. The LM $\alpha 5$ (laminin $\alpha 5$ )derived peptide A5G27 binds to the glycosaminoglycan chains of CD44, preventing its binding to FGF2 and inhibiting angiogenesis [137]. The heparin-binding lactoferrin fragment LfcinB inhibits the angiogenic activity of FGF2 by binding to HSPGs on endothelial cells [138]. Protamine [139], several CXCL4-derived peptides, the histidine-rich glycoprotein [140] and antithrombin [141] exhibit antiangiogenic properties, whose mechanism of action may rely, at least in part, on their capacity to bind and mask HSPGs to FGFs. Finally, the cholera toxin B subunit inhibits FGF2-dependent proliferation of endothelial cells by hampering the binding of the angiogenic growth factor to cell surface $\mathrm{GM}_{1}$ ganglioside [111].

\subsection{Inhibition of signal transduction triggered by FGFR activation}

As already mentioned, the first step of the activation of the FGF/FGFR system is represented by the receptor dimerization and autophosphorylation. As for other TK receptors, inhibition of the TK activity of FGFRs by selective or non-selective molecules has been deeply exploited for the discovery of novel antitumor drugs for the treatment of FGF-dependent tumors. Tyrosine kinase inhibitors (TKIs) have been developed as small molecules acting on the ATPbinding pocket of the intracellular TK domain of the receptor. Some of them, like SU5402 and PD173034, are widely used as FGFR inhibitors in the laboratory practice even though clinical applications are limited by their toxicity [142].

A consistent number of wide-spectrum/non-selective TKIs have been shown to block FGFRs and their mechanism of action and therapeutic application have been associated to their capacity to interfere with multiple TK receptor pathways, including FGFRs. Among them, regorafenib is a novel orally active multitarget compound that inhibits a number of pro-angiogenic TK receptors, including FGFR1, VEGFR2, TIE2, and PDGFR [143]; nintedanib (BIBF1120) interferes with VEGFR, PDGFR and FGFR pathways [144]; ponatinib (AP24534), mainly active on BCR-ABL, has been described to exert an anti-FGFR activity in vitro [145]. Several other small molecules, including axitinib, brivanib, cabozantinib, dovotinib, oratinib, pazopamib, sorafenib, sunitinib and vandetanib are endowed with this non-selective TKI profile (see Refs. [146,147] for more details).

All these multi-targeting TKIs are endowed with toxicity profiles often related to their anti-VEGFR action, such as cardiovascular or hypertensive drawbacks or proteinuria, or with other side effects, like gastrointestinal disorders or skin reactions. On the other hand, few selective FGFR inhibitors have been characterized and evaluated in clinical trials. AZD4547 (a pan-FGFR inhibitor), BGJ398 (that targets FGFR1, FGFR2 and FGFR3) and LY287445 (a pan-FGFR inhibitor) are under clinical evaluation for different types of cancer characterized by FGFR amplification or activating mutations. These new "FGFR-restricted" drugs show better tolerability in respect to non-selective TKIs, their most relevant side effects (hyperphosphatemia and tissue calcification) being strictly correlated to the inhibition of the FGF23 pathway.
Apart from intracellular-acting TKIs, recent observations have shown that the small molecule SSR128129E can bind the extracellular portion of FGFRs and inhibit FGFR signalling by an allosteric mechanism of action, without affecting the orthosteric binding of FGF to the receptor [148].

The interaction of the different FGFs with the various TK FGFRs leads to the activation of signal transduction pathways that share, at least in part, several intracellular second messengers in stromal and tumor cells, representing potential therapeutic targets. To this aim, synthetic compounds, dominant negative mutants and antisense cDNAs have been tested for their capacity to shut down a deregulated FGF/FGFR system (Table 3). However, as already pointed out for heparin-like FGF inhibitors, the broad spectrum of action of these intracellular inhibitors must be carefully evaluated for their potential multitarget activity and undesired side effects.

\section{Concluding remarks}

The study of the mechanisms of action of FGFs has led to the identification of various molecules that can modulate the aberrant activation of the FGF/FGFR system in different human cancers.

Due to their pleiotropic nature, FGFs may contribute to cancer progression not only by triggering a pro-angiogenic response but also by acting directly on tumor cells via paracrine and autocrine loops of stimulation. Thus, targeting the FGF/FGFR system through "two-compartment" anti-FGF/FGFR agents may provide benefits not only in terms of inhibition of the neovascularization process but also by an oncosuppressive effect on tumor cells, thus hampering the tumor stromal/parenchymal cross-talk.

As described above, a wide array of approaches might be theoretically pursued to develop anti-FGF/FGFR strategies for the treatment of human cancers. For all these approaches, the demonstration of their efficacy has been provided in vitro and the antiangiogenic/antitumor potential has been proven in vivo in preclinical models for many of them. Nevertheless, the search for anti-FGF/FGFR drugs currently under evaluation in cancer clinical trials (https://clinicaltrials.gov) indicates that only two major classes of inhibitors of the FGF/FGFR system have been developed so far: FGFR selective and nonselective TKIs and anti-FGFR antibodies, a few studies focusing on FGFR decoy extracellular FGF ligand traps (see Refs. [146,149-153] for a detailed description of FGF/FGFR-targeting agents in phase I, phase II or phase III clinical development). In addition, it is worth noting that FGF/FGFR inhibitors are frequently evaluated in combination with classical chemotherapeutics, in agreement with the notion that, in respect to monotherapies, multidrug regimens may provide better therapeutic benefits in cancer patients. To this respect, the observation that the escape from angiostatic anti-VEGF blockade can be mediated by the upregulation of the FGF/FGFR system [154,155] points to the possibility that the combinatorial or sequential inhibition of VEGF and FGF pathways may translate into improvements in the clinical care of cancer patients. Finally, various compounds like integrin antagonists and heparin, that entered clinical trials for different pharmacologic features, have been evaluated afterwards also for anti-FGF/FGFR potential.

In conclusion, experimental and clinical evidences point to a role for the FGF/FGFR system in tumor neovascularization, growth and metastatic dissemination. However, several challenges are being faced to further develop efficacious FGF/FGFR inhibitors for antiangiogenic/antitumor therapies in cancer. They include, among others; i) identification of cancer patients more likely to benefit from a therapeutic anti-FGF/FGFR approach; ii) identification of prognostic indicators, surrogate markers of angiogenesis and of response to anti-FGF/FGFR therapies in cancer patients; iii) elucidation of the pros and cons about the use of selective 
versus nonselective inhibitors; iv) development of drugs specific for individual FGFs or FGFRs that may reduce undesired systemic side-effects related also to alterations of hormone-like FGFs. Relevant to this latter point, blockade of FGFR signalling by selective or broad-spectrum TK inhibitors has been associated with toxicity [146] and a monoclonal antibody directed against FGFR1 has failed because of severe weight loss associated with hypothalamic binding [156]. Interestingly, at variance with the hyperphosphatemic effect of FGFR TK inhibitors in preclinical models [157] and cancer patients [146], long-term administration of the small molecule FGF trap NSC12 does not affect the blood levels of phosphorus, calcium and FGF23 in tumor-bearing mice [120]. These observations are in keeping with the safety profile in murine tumor models of the FGFR1-derived FGF trap FP-1039 [124] and of the allosteric multiFGFR blocker SSR128129E [148]. Together, these findings suggest that hyperphosphatemia may represent a side effect of FGFR TK inhibitors rather than of extracellular inhibitors of the FGF/FGFR system. Given that both FGF23 expression and activity are under the control of a complex mechanism of regulation that includes canonical, non-canonical and intracrine FGF/FGFR pathways [158], further studies are required to elucidate this point.

\section{Conflict of interest}

The authors declare that there are no conflicts of interest.

\section{Acknowledgments}

This work was supported by grants from Ministero Istruzione, Università e Ricerca (FIRB project RBAP11H2R9 2011) and Associazione Italiana Ricerca sul Cancro (AIRC grant $n^{\circ}$ 14395) to M.P. A.G, S.M. and P.C. were supported by Fondazione Italiana per la Ricerca sul Cancro Fellowships.

\section{References}

[1] N. Itoh, D.M. Ornitz, Functional evolutionary history of the mouse Fgf gene family, Dev. Dyn. 237 (1) (2008) 18-27 (Epub 2007/12/07)

[2] A. Beenken, M. Mohammadi, The FGF family: biology, pathophysiology and therapy, Nat. Rev. Drug Discov. 8 (3) (2009) 235-253 (Epub 2009/02/28).

[3] C. Richard, J.P. Liuzzo, D. Moscatelli, Fibroblast growth factor-2 can mediate cell attachment by linking receptors and heparan sulfate proteoglycans on neighboring cells, J. Biol. Chem. 270 (41) (1995) 24188-24196 (Epub 1995/10/13)

[4] U. Hacker, K. Nybakken, N. Perrimon, Heparan sulphate proteoglycans: the sweet side of development, Nat. Rev. Mol. Cell Biol. 6 (7) (2005) 530-541 (Epub 2005/08/03).

[5] M. Goldfarb, J. Schoorlemmer, A. Williams, S. Diwakar, Q. Wang, X. Huang, et al., Fibroblast growth factor homologous factors control neuronal excitability through modulation of voltage-gated sodium channels, Neuron 55 (3) (2007) 449-463 (Epub 2007/08/07).

[6] H. Kurosu, Y. Ogawa, M. Miyoshi, M. Yamamoto, A. Nandi, K.P. Rosenblatt, et al., Regulation of fibroblast growth factor-23 signaling by klotho, J. Biol. Chem. 281 (10) (2006) 6120-6123 (Epub 2006/01/27).

[7] M.S. Razzaque, The FGF23-Klotho axis: endocrine regulation of phosphate homeostasis, Nat. Rev. Endocrinol. 5 (11) (2009) 611-619 (Epub 2009/10/22)

[8] T. Inagaki, M. Choi, A. Moschetta, L. Peng, C.L. Cummins, J.G. McDonald, et al. Fibroblast growth factor 15 functions as an enterohepatic signal to regulate bile acid homeostasis, Cell Metab. 2 (4) (2005) 217-225 (Epub 2005/10/11)

[9] T. Inagaki, P. Dutchak, G. Zhao, X. Ding, L. Gautron, V. Parameswara, et al., Endocrine regulation of the fasting response by PPARalpha-mediated induction of fibroblast growth factor 21, Cell Metab. 5 (6) (2007) 415-425 (Epub 2007/06/07).

[10] N. Itoh, Hormone-like (endocrine) Fgfs: their evolutionary history and roles in development, metabolism, and disease, Cell Tissue Res. 342 (1) (2010) $1-11$ (Epub 2010/08/24)

[11] M. Mohammadi, S.K. Olsen, O.A. Ibrahimi, Structural basis for fibroblast growth factor receptor activation, Cytokine Growth Factor Rev. 16 (2) (2005) 107-137 (Epub 2005/05/03).

[12] V.P. Eswarakumar, I. Lax, J. Schlessinger, Cellular signaling by fibroblast growth factor receptors, Cytokine Growth Factor Rev. 16 (2) (2005) 139-149 (Epub 2005/05/03).

[13] B.K. Yeh, M. Igarashi, A.V. Eliseenkova, A.N. Plotnikov, I. Sher, D. Ron, et al., Structural basis by which alternative splicing confers specificity in fibroblast growth factor receptors, Proc. Natl. Acad. Sci. U. S. A. 100 (5) (2003) 2266-2271 (Epub 2003/02/20)

[14] J. Schlessinger, A.N. Plotnikov, O.A. Ibrahimi, A.V. Eliseenkova, B.K. Yeh, A. Yayon, et al., Crystal structure of a ternary FGF-FGFR-heparin complex reveals a dual role for heparin in FGFR binding and dimerization, Mol. Cell 6 (3) (2000) 743-750 (Epub 2000/10/13).

[15] A.N. Brooks, E. Kilgour, P.D. Smith, Molecular pathways: fibroblast growth factor signaling: a new therapeutic opportunity in cancer, Clin. Cancer Res. 18 (7) (2012) 1855-1862 (Epub 2012/03/06).

[16] S. Kang, S. Elf, S. Dong, T. Hitosugi, K. Lythgoe, A. Guo, et al., Fibroblast growth factor receptor 3 associates with and tyrosine phosphorylates p90 RSK2, leading to RSK2 activation that mediates hematopoietic transformation, Mol. Cell. Biol. 29 (8) (2009) 2105-2117 (Epub 2009/02/19).

[17] J.F. Reilly, E. Mizukoshi, P.A. Maher, Ligand dependent and independent internalization and nuclear translocation of fibroblast growth factor (FGF) receptor 1, DNA Cell Biol. 23 (9) (2004) 538-548 (Eub 2004/09/24).

[18] L. Duchesne, B. Tissot, T.R. Rudd, A. Dell, D.G. Fernig, N-glycosylation of fibroblast growth factor receptor 1 regulates ligand and heparan sulfate co-receptor binding, J. Biol. Chem. 281 (37) (2006) 27178-27189 (Epub 2006/07/11).

[19] N.E. Hatch, M. Hudson, M.L. Seto, M.L. Cunningham, M. Bothwell, Intracellular retention, degradation, and signaling of glycosylation-deficient FGFR2 and craniosynostosis syndrome-associated FGFR2C278F, J. Biol. Chem. 281 (37) (2006) 27292-27305 (Epub 2006/07/18)

[20] N. Gotoh, Regulation of growth factor signaling by FRS2 family docking/scaffold adaptor proteins, Cancer Sci. 99 (7) (2008) 1319-1325 (Epub 2008/05/03).

[21] T. Casci, J. Vinos, M. Freeman, Sprouty, an intracellular inhibitor of Ras signaling, Cell 96 (5) (1999) 655-665 (Epub 1999/03/25).

[22] Y. Zhao, Z.Y. Zhang, The mechanism of dephosphorylation of extracellular signal-regulated kinase 2 by mitogen-activated protein kinase phosphatase 3. J. Biol. Chem. 276 (34) (2001) 32382-32391 (Epub 2001/07/04)

[23] N.J. Harmer, L.L. Ilag, B. Mulloy, L. Pellegrini, C.V. Robinson, T.L. Blundell, Towards a resolution of the stoichiometry of the fibroblast growth factor (FGF)-FGF receptor-heparin complex, J. Mol. Biol. 339 (4) (2004) 821-834 (Epub 2004/05/29)

[24] M. Rusnati, C. Urbinati, E. Tanghetti, P. Dell'Era, H. Lortat-Jacob, M. Presta, Cell membrane GM1 ganglioside is a functional coreceptor for fibroblast growth factor 2, Proc. Natl. Acad. Sci. U. S. A. 99 (7) (2002) 4367-4372 (Epub $2002 / 03 / 28)$

[25] M. Rusnati, E. Tanghetti, P. Dell'Era, A. Gualandris, Presta M. alphavbeta3 integrin mediates the cell-adhesive capacity and biological activity of basic fibroblast growth factor (FGF-2) in cultured endothelial cells, Mol. Biol. Cell 8 (12) (1997) 2449-2461 (Epub 1997/12/17).

[26] E. Tanghetti, R. Ria, P. Dell'Era, C. Urbinati, M. Rusnati, M.G. Ennas, et al., Biological activity of substrate-bound basic fibroblast growth factor (FGF2): recruitment of FGF receptor-1 in endothelial cell adhesion contacts, Oncogene 21 (24) (2002) 3889-3897 (Epub 2002/05/29).

[27] E. Sanchez-Heras, F.V. Howell, G. Williams, P. Doherty, The fibroblast growth factor receptor acid box is essential for interactions with $\mathrm{N}$-cadherin and all of the major isoforms of neural cell adhesion molecule, J. Biol. Chem. 281 (46) (2006) 35208-35216 (Epub 2006/09/29).

[28] N. Kulahin, S. Li, A. Hinsby, V. Kiselyov, V. Berezin, E. Bock, Fibronectin type III (FN3) modules of the neuronal cell adhesion molecule L1 interact directly with the fibroblast growth factor (FGF) receptor, Mol. Cell. Neurosci. 37 (3) (2008) 528-536 (Epub 2008/01/29).

[29] D. Gonzalez-Martinez, S.H. Kim, Y. Hu, S. Guimond, J. Schofield, P. Winyard, et al., Anosmin-1 modulates fibroblast growth factor receptor 1 signaling in human gonadotropin-releasing hormone olfactory neuroblasts through a heparan sulfate-dependent mechanism, J. Neurosci. 24 (46) (2004) 10384-10392 (Epub 2004/11/19)

[30] H. Yokote, K. Fujita, X. Jing, T. Sawada, S. Liang, L. Yao, et al., Trans-activation of EphA4 and FGF receptors mediated by direct interactions between their cytoplasmic domains, Proc. Natl. Acad. Sci. U. S. A. 102 (52) (2005) 18866-18871 (Epub 2005/12/21).

[31] J. Folkman, Role of angiogenesis in tumor growth and metastasis, Semin. Oncol. 29 (Suppl. 16) (2002) 15-18 (Epub 2003/01/08).

[32] J. Folkman, D. Hanahan, Switch to the angiogenic phenotype during tumorigenesis, Princess Takamatsu Symp. 22 (1991) 339-347 (. Epub $1991 / 01 / 01)$

[33] Y. Shing, J. Folkman, R. Sullivan, C. Butterfield, J. Murray, M. Klagsbrun, Heparin affinity: purification of a tumor-derived capillary endothelial cell growth factor, Science 223 (4642) (1984) 1296-1299.

[34] T. Maciag, T. Mehlman, R. Friesel, A.B. Schreiber, Heparin binds endothelial cell growth factor, the principal endothelial cell mitogen in bovine brain, Science 225 (4665) (1984) 932-935.

[35] D. Ribatti, A. Vacca, L. Roncali, F. Dammacco, The chick embryo chorioallantoic membrane as a model for in vivo research on anti-angiogenesis, Curr. Pharm. Biotechnol. 1 (1) (2000) 73-82 (Epub 2001/07/27)

[36] G. Seghezzi, S. Patel, C.J. Ren, A. Gualandris, G. Pintucci, E.S. Robbins, et al., Fibroblast growth factor-2 (FGF-2) induces vascular endothelial growth factor (VEGF) expression in the endothelial cells of forming capillaries: an autocrine mechanism contributing to angiogenesis, J. Cell Biol. 141 (7) (1998) 1659-1673 (Epub 1998/07/01). 
[37] D. Coltrini, E. Di Salle, R. Ronca, M. Belleri, C. Testini, M. Presta, Matrigel plug assay: evaluation of the angiogenic response by reverse transcription-quantitative PCR, Angiogenesis 16 (2) (2013) 469-477 (Epub 2012/11/13).

[38] R. Ronca, A. Giacomini, M. Rusnati, M. Presta, The potential of fibroblast growth factor/fibroblast growth factor receptor signaling as a therapeutic target in tumor angiogenesis, Expert Opin. Ther. Targets (2015) 1-17 (Epub 2015/07/01.).

[39] D.L. Miller, S. Ortega, O. Bashayan, R. Basch, C. Basilico, Compensation by fibroblast growth factor 1 (FGF1) does not account for the mild phenotypic defects observed in FGF2 null mice, Mol. Cell. Biol. 20 (6) (2000) 2260-2268 (Epub 2000/02/25).

[40] M. Antoine, W. Wirz, C.G. Tag, M. Mavituna, N. Emans, T. Korff, et al., Expression pattern of fibroblast growth factors (FGFs), their receptors and antagonists in primary endothelial cells and vascular smooth muscle cells, Growth Factors 23 (2) (2005) 87-95 (Epub 2005/07/16).

[41] S.S. Oladipupo, C. Smith, A. Santeford, C. Park, A. Sene, L.A. Wiley, et al., Endothelial cell FGF signaling is required for injury response but not for vascular homeostasis, Proc. Natl. Acad. Sci. U. S. A. 111 (37) (2014) 13379-13384 (Epub 2014/08/21).

[42] S. Javerzat, P. Auguste, A. Bikfalvi, The role of fibroblast growth factors in vascular development, Trends Mol. Med. 8 (10) (2002) 483-489.

[43] M.M. Mattila, J.K. Ruohola, E.M. Valve, M.J. Tasanen, J.A. Seppanen, P.L. Harkonen, FGF-8b increases angiogenic capacity and tumor growth of androgen-regulated S115 breast cancer cells, Oncogene 20 (22)(2001) 2791-2804 (Epub 2001/06/23).

[44] G. Pintucci, P.J. Yu, R. Sharony, F.G. Baumann, F. Saponara, A. Frasca, et al., Induction of stromelysin-1 (MMP-3) by fibroblast growth factor-2 (FGF-2) in FGF-2-/- microvascular endothelial cells requires prolonged activation of extracellular signal-regulated kinases-1 and -2 (ERK-1/2), J. Cell. Biochem. 90 (5) (2003) 1015-1025 (Epub 2003/11/19).

[45] G. Taraboletti, S. D’Ascenzo, P. Borsotti, R. Giavazzi, A. Pavan, V. Dolo, Shedding of the matrix metalloproteinases MMP-2, MMP-9, and MT1-MMP as membrane vesicle-associated components by endothelial cells, Am. J. Pathol. 160 (2) (2002) 673-680 (Epub 2002/02/13).

[46] M. Antoine, W. Wirz, C.G. Tag, A.M. Gressner, M. Wycislo, R. Muller, et al. Fibroblast growth factor 16 and 18 are expressed in human cardiovascular tissues and induce on endothelial cells migration but not proliferation, Biochem. Biophys. Res. Commun. 346 (1) (2006) 224-233 (Epub 2006/06/08).

[47] C. Greenman, P. Stephens, R. Smith, G.L. Dalgliesh, C. Hunter, G. Bignell, et al., Patterns of somatic mutation in human cancer genomes, Nature 446 (7132) (2007) 153-158

[48] D. Cappellen, C. De Oliveira, D. Ricol, S. de Medina, J. Bourdin, X. Sastre-Garau, et al., Frequent activating mutations of FGFR3 in human bladder and cervix carcinomas, Nat. Genet. 23 (1) (1999) 18-20.

[49] E. di Martino, C.G. L'Hote, W. Kennedy, D.C. Tomlinson, M.A. Knowles, Mutant fibroblast growth factor receptor 3 induces intracellular signaling and cellular transformation in a cell type- and mutation-specific manner, Oncogene 28 (48) (2009) 4306-4316.

[50] C. Rosty, M.H. Aubriot, D. Cappellen, J. Bourdin, I. Cartier, J.P. Thiery, et al. Clinical and biological characteristics of cervical neoplasias with FGFR3 mutation, Mol. Cancer 4 (1) (2005) 15.

[51] A. Kalff, A. Spencer, The $t(4 ; 14)$ translocation and FGFR3 overexpression in multiple myeloma: prognostic implications and current clinical strategies, Blood Cancer J. 2 (2012) e89.

[52] M. Chesi, E. Nardini, L.A. Brents, E. Schrock, T. Ried, W.M. Kuehl, et al., Frequent translocation $\mathrm{t}(4 ; 14)(\mathrm{p} 16.3 ; \mathrm{q} 32.3)$ in multiple myeloma is associated with increased expression and activating mutations of fibroblast growth factor receptor 3, Nat. Genet. 16 (3) (1997) 260-264.

[53] S. Hernandez, S. de Muga, L. Agell, N. Juanpere, R. Esgueva, J.A. Lorente, et al., FGFR3 mutations in prostate cancer: association with low-grade tumors, Modern Pathol. 22 (6) (2009) 848-856.

[54] A. Goriely, R.M. Hansen, I.B. Taylor, I.A. Olesen, G.K. Jacobsen, S.J. McGowan, et al., Activating mutations in FGFR3 and HRAS reveal a shared genetic origin for congenital disorders and testicular tumors, Nat. Genet. 41 (11) (2009) 1247-1252.

[55] Y. Zhang, Y. Hiraishi, H. Wang, K.S. Sumi, Y. Hayashido, S. Toratani, et al., Constitutive activating mutation of the FGFR3b in oral squamous cell carcinomas, Int. J. Cancer 117 (1) (2005) 166-168.

[56] J.G.t Taylor, A.T. Cheuk, P.S. Tsang, J.Y. Chung, Y.K. Song, K. Desai, et al., Identification of FGFR4-activating mutations in human rhabdomyosarcomas that promote metastasis in xenotransplanted models, J. Clin. Invest. 119 (11) (2009) 3395-3407.

[57] W.M. Abdel-Rahman, J. Kalinina, S. Shoman, S. Eissa, M. Ollikainen, O. Elomaa, et al., Somatic FGF9 mutations in colorectal and endometrial carcinomas associated with membranous beta-catenin, Hum. Mutat. 29 (3) (2008) 390-397.

[58] A. Fischbach, A. Rogler, R. Erber, R. Stoehr, R. Poulsom, A. Heidenreich, et al., Fibroblast growth factor receptor (FGFR) gene amplifications are rare events in bladder cancer, Histopathology 66 (5) (2015) 639-649.

[59] F. Courjal, M. Cuny, J. Simony-Lafontaine, G. Louason, P. Speiser, R. Zeillinger, et al., Mapping of DNA amplifications at 15 chromosomal localizations in 1875 breast tumors: definition of phenotypic groups, Cancer Res. 57 (19) (1997) 4360-4367.
[60] R.S. Heist, M. Mino-Kenudson, L.V. Sequist, S. Tammireddy, L. Morrissey, D.C Christiani, et al., FGFR1 amplification in squamous cell carcinoma of the lung, J. Thorac. Oncol. 7 (12) (2012) 1775-1780.

[61] T. Jiang, G. Gao, G. Fan, M. Li, C. Zhou, FGFR1 amplification in lung squamous cell carcinoma: a systematic review with meta-analysis, Lung Cancer 87 (1) (2015) 1-7.

[62] K. Freier, C. Schwaenen, C. Sticht, C. Flechtenmacher, J. Muhling, C. Hofele, et al., Recurrent FGFR1 amplification and high FGFR1 protein expression in oral squamous cell carcinoma (OSCC), Oral Oncol. 43 (1) (2007) 60-66.

[63] K.L. Gorringe, S. Jacobs, E.R. Thompson, A. Sridhar, W. Qiu, D.Y. Choong, et al, High-resolution single nucleotide polymorphism array analysis of epithelial ovarian cancer reveals numerous microdeletions and amplifications, Clin. Cancer Res. 13 (16) (2007) 4731-4739.

[64] E. Missiaglia, J. Selfe, M. Hamdi, D. Williamson, G. Schaaf, C. Fang, et al., Genomic imbalances in rhabdomyosarcoma cell lines affect expression of genes frequently altered in primary tumors: an approach to identify candidate genes involved in tumor development, Genes Chromosomes Cancer 48 (6) (2009) 455-467.

[65] K. Kunii, L. Davis, J. Gorenstein, H. Hatch, M. Yashiro, A. Di Bacco, et al., FGFR2-amplified gastric cancer cell lines require FGFR2 and Erbb3 signaling for growth and survival, Cancer Res. 68 (7) (2008) 2340-2348.

[66] A. Bai, K. Meetze, N.Y. Vo, S. Kollipara, E.K. Mazsa, W.M. Winston, et al., GP369, an FGFR2-IIIb-specific antibody, exhibits potent antitumor activity against human cancers driven by activated FGFR2 signaling, Cancer Res. 70 (19) (2010) 7630-7639.

[67] S. Roumiantsev, D.S. Krause, C.A. Neumann, C.A. Dimitri, F. Asiedu, N.C. Cross, et al., Distinct stem cell myeloproliferative/T lymphoma syndromes induced by ZNF198-FGFR1 and BCR-FGFR1 fusion genes from 8p11 translocations, Cancer Cell 5 (3) (2004) 287-298.

[68] F. Yagasaki, D. Wakao, Y. Yokoyama, Y. Uchida, I. Murohashi, H. Kayano, et al., Fusion of ETV6 to fibroblast growth factor receptor 3 in periphera T-cell lymphoma with a t(4;12)(p16;p13) chromosomal translocation, Cancer Res. 61 (23) (2001) 8371-8374 (Epub 2001/12/04).

[69] T. Otsuki, O. Yamada, K. Yata, H. Sakaguchi, J. Kurebayashi, N. Nakazawa, et al., Expression of fibroblast growth factor and FGF-receptor family genes in human myeloma cells, including lines possessing $\mathrm{t}(4 ; 14)(\mathrm{q} 16.3 ; \mathrm{q} 323)$ and FGFR3 translocation, Int. J. Oncol. 15 (6) (1999) 1205-1212.

[70] S.V. Williams, C.D. Hurst, M.A. Knowles, Oncogenic FGFR3 gene fusions in bladder cancer, Hum. Mol. Genet. 22 (4) (2013) 795-803.

[71] D. Daphna-Iken, D.B. Shankar, A. Lawshe, D.M. Ornitz, G.M. Shackleford, C.A. MacArthur, MMTV-Fgf8 transgenic mice develop mammary and salivary gland neoplasia and ovarian stromal hyperplasia, Oncogene 17 (21) (1998) 2711-2717.

[72] C. Zhong, G. Saribekyan, C.P. Liao, M.B. Cohen, P. Roy-Burman, Cooperation between FGF8b overexpression and PTEN deficiency in prostate tumorigenesis, Cancer Res. 66 (4) (2006) 2188-2194.

[73] J.C. Clark, J.W. Tichelaar, S.E. Wert, N. Itoh, A.K. Perl, M.T. Stahlman, et al., FGF-10 disrupts lung morphogenesis and causes pulmonary adenomas in vivo, Am. J. Physiol. Lung Cell. Mol. Physiol. 280 (4) (2001) L705-15.

[74] Y. Wang, D. Becker, Antisense targeting of basic fibroblast growth factor and fibroblast growth factor receptor-1 in human melanomas blocks intratumoral angiogenesis and tumor growth, Nat. Med. 3 (8) (1997) 887-893.

[75] M.J. Birrer, M.E. Johnson, K. Hao, K.K. Wong, D.C. Park, A. Bell, et al., Whole genome oligonucleotide-based array comparative genomic hybridization analysis identified fibroblast growth factor 1 as a prognostic marker for advanced-stage serous ovarian adenocarcinomas, J. Clin. Oncol. 25 (16) (2007) 2281-2287

[76] L. Marek, K.E. Ware, A. Fritzsche, P. Hercule, W.R. Helton, J.E. Smith, et al., Fibroblast growth factor (FGF) and FGF receptor-mediated autocrine signaling in non-small-cell lung cancer cells, Mol. Pharmacol. 75 (1) (2009) 196-207.

[77] M.E. Marshall, T.K. Hinz, S.A. Kono, K.R. Singleton, B. Bichon, K.E. Ware, et al., Fibroblast growth factor receptors are components of autocrine signaling networks in head and neck squamous cell carcinoma cells, Clin. Cancer Res. 17 (15) (2011) 5016-5025.

[78] S. Memarzadeh, L. Xin, D.J. Mulholland, A. Mansukhani, H. Wu, M.A. Teitell, et al., Enhanced paracrine FGF10 expression promotes formation of multifocal prostate adenocarcinoma and an increase in epithelial androgen receptor, Cancer Cell 12 (6) (2007) 572-585 (Epub 2007/12/11).

[79] R.T. Poon, S.T. Fan, J. Wong, Clinical implications of circulating angiogenic factors in cancer patients, J. Clin. Oncol. 19 (4) (2001) 1207-1225.

[80] A. Ori, M.C. Wilkinson, D.G. Fernig, The heparanome and regulation of cell function: structures, functions and challenges, Front. Biosci: J. Virt. Libr. 13 (2008) 4309-4338

[81] M. Presta, P. Dell'Era, S. Mitola, E. Moroni, R. Ronca, M. Rusnati, Fibroblast growth factor/fibroblast growth factor receptor system in angiogenesis, Cytokine Growth Factor Rev. 16 (2) (2005) 159-178 (Epub 2005/05/03)

[82] K. Polyak, I. Haviv, I.G. Campbell, Co-evolution of tumor cells and their microenvironment, Trends Genet.: TIG 25 (1) (2009) 30-38.

[83] B. Vogelstein, K.W. Kinzler, Cancer genes and the pathways they control, Nat. Med. 10 (8) (2004) 789-799.

[84] K. Pietras, A. Ostman, Hallmarks of cancer: interactions with the tumor stroma, Exp. Cell Res. 316 (8) (2010) 1324-1331. 
[85] D.W. McMillin, J.M. Negri, C.S. Mitsiades, The role of tumour-stromal interactions in modifying drug response: challenges and opportunities, Nat Rev. Drug Discov. 12 (3) (2013) 217-228.

[86] B. Kwabi-Addo, M. Ozen, M. Ittmann, The role of fibroblast growth factors and their receptors in prostate cancer, Endocr. Relat. Cancer 11 (4) (2004) 709-724 (Epub 2004/12/23)

[87] R. Ronca, P. Alessi, D. Coltrini, E. Di Salle, A. Giacomini, D. Leali, et al., Long pentraxin-3 as an epithelial-stromal fibroblast growth factor-targeting inhibitor in prostate cancer, J. Pathol. 230 (2) (2013) 228-238 (Epub 2013/02/21).

[88] F. Ropiquet, D. Giri, B. Kwabi-Addo, K. Schmidt, Ittmann M: FGF-10 is expressed at low levels in the human prostate, Prostate 44 (4) (2000) 334-338.

[89] K. Ishii, T. Imamura, K. Iguchi, S. Arase, Y. Yoshio, K. Arima, et al., Evidence that androgen-independent stromal growth factor signals promote androgen-insensitive prostate cancer cell growth in vivo, Endocr. Relat. Cancer 16 (2) (2009) 415-428.

[90] M. Musumeci, V. Coppola, A. Addario, M. Patrizii, M. Maugeri-Sacca, L. Memeo, et al., Control of tumor and microenvironment cross-talk by miR-15a and miR-16 in prostate cancer, Oncogene 30 (41) (2011) 4231-4242.

[91] R. Ronca, E. Di Salle, A. Giacomini, D. Leali, P. Alessi, D. Coltrini, et al., Long pentraxin-3 inhibits epithelial-mesenchymal transition in melanoma cells, Mol. Cancer Ther. 12 (12) (2013) 2760-2771 (Epub 2013/10/17).

[92] T.Y. Chu, J.T. Yang, T.H. Huang, H.W. Liu, Crosstalk with cancer-associated fibroblasts increases the growth and radiation survival of cervical cancer cells, Radiat. Res. 181 (5) (2014) 540-547.

[93] D. Mahadevan, D.D. Von Hoff, Tumor-stroma interactions in pancreatic ductal adenocarcinoma, Mol. Cancer Ther. 6 (4) (2007) 1186-1197.

[94] I. Esposito, M. Menicagli, N. Funel, F. Bergmann, U. Boggi, F. Mosca, et al., Inflammatory cells contribute to the generation of an angiogenic phenotype in pancreatic ductal adenocarcinoma, J. Clin. Pathol. 57 (6) (2004) 630-636.

[95] S. Saito, K. Morishima, T. Ui, H. Hoshino, D. Matsubara, S. Ishikawa, et al., The role of HGF/MET and FGF/FGFR in fibroblast-derived growth stimulation and lapatinib-resistance of esophageal squamous cell carcinoma, BMC Cancer 15 (2015) 82.

[96] F. Di Raimondo, M.P. Azzaro, G. Palumbo, S. Bagnato, G. Giustolisi, P. Floridia, et al., Angiogenic factors in multiple myeloma: higher levels in bone marrow than in peripheral blood, Haematologica 85 (8) (2000) 800-805.

[97] N. Sato, Y. Hattori, D. Wenlin, T. Yamada, T. Kamata, T. Kakimoto, et al., Elevated level of plasma basic fibroblast growth factor in multiple myeloma correlates with increased disease activity, Jpn. J. Cancer Res: Gann 93 (4) (2002) 459-466.

[98] G. Bisping, R. Leo, D. Wenning, B. Dankbar, T. Padro, M. Kropff, et al., Paracrine interactions of basic fibroblast growth factor and interleukin-6 in multiple myeloma, Blood 101 (7) (2003) 2775-2783.

[99] K. Bommert, R.C. Bargou, T. Stuhmer, Signalling and survival pathways in multiple myeloma, Eur. J. Cancer 42 (11) (2006) 1574-1580.

[100] M. Presta, G. Andres, D. Leali, P. Dell'Era, R. Ronca, Inflammatory cells and chemokines sustain FGF2-induced angiogenesis, Eur. Cytokine Netw. 20 (2) (2009) 39-50 (Epub 2009/06/23).

[101] G. Cassinelli, C. Lanzi, R. Supino, G. Pratesi, V. Zuco, D. Laccabue, et al., Cellular bases of the antitumor activity of the novel taxane IDN 5109 (BAY59-8862) on hormone-refractory prostate cancer, Clin. Cancer Res. 8 (8) (2002) 2647-2654

[102] K.A. Hotchkiss, A.W. Ashton, R. Mahmood, R.G. Russell, J.A. Sparano, E.L. Schwartz, Inhibition of endothelial cell function in vitro and angiogenesis in vivo by docetaxel (Taxotere): association with impaired repositioning of the microtubule organizing center, Mol. Cancer Ther. 1 (13) (2002) 1191-1200.

[103] E. Cenni, F. Perut, D. Granchi, S. Avnet, I. Amato, M.L. Brandi, et al., Inhibition of angiogenesis via FGF-2 blockage in primitive and bone metastatic renal cell carcinoma, Anticancer Res. 27 (1A) (2007) 315-319 (Epub 2007/03/14)

[104] M. Rusnati, M. Presta, Fibroblast growth factors/fibroblast growth factor receptors as targets for the development of anti-angiogenesis strategies, Curr. Pharm. Des. 13 (20) (2007) 2025-2044

[105] C.H. Chen, W. Jiang D.P. Via, S. Luo, T.R. Li, Y.T. Lee, et al., Oxidized low-density lipoproteins inhibit endothelial cell proliferation by suppressing basic fibroblast growth factor expression, Circulation 101 (2) (2000) 171-177 (Epub 2000/01/19).

[106] S. Huang, C.D. Bucana, M. Van Arsdall, I.J. Fidler, Stat1 negatively regulates angiogenesis, tumorigenicity and metastasis of tumor cells, Oncogene 21 (16) (2002) 2504-2512.

[107] K. Norioka, T. Mitaka, Y. Mochizuki, M. Hara, M. Kawagoe, H. Nakamura, Interaction of interleukin-1 and interferon-gamma on fibroblast growth factor-induced angiogenesis, Jpn. J. Cancer Res. 85 (5) (1994) 522-529.

[108] C.C. Chua, N. Rahimi, K. Forsten-Williams, M.A. Nugent, Heparan sulfate proteoglycans function as receptors for fibroblast growth factor-2 activation of extracellular signal-regulated kinases 1 and 2, Circ. Res. 94 (3) (2004) 316-323.

[109] P. Auguste, D.B. Gursel, S. Lemiere, D. Reimers, P. Cuevas, F. Carceller, et al., Inhibition of fibroblast growth factor/fibroblast growth factor receptor activity in glioma cells impedes tumor growth by both angiogenesis-dependent and -independent mechanisms, Cancer Res. 61 (4) (2001) 1717-1726 (Epub 2001/03/14).
[110] W. Zhang, Y.J. Chuang, R. Swanson, J. Li, K. Seo, L. Leung, et al., Antiangiogenic antithrombin down-regulates the expression of the proangiogenic heparan sulfate proteoglycan, perlecan, in endothelial cells, Blood 103 (4) (2004) 1185-1191.

[111] M. Rusnati, C. Urbinati, E. Tanghetti, P. Dell'Era, H. Lortat-Jacob, M. Presta, Cell membrane GM1 ganglioside is a functional coreceptor for fibroblast growth factor 2, Proc. Natl. Acad. Sci. U. S. A. 99 (7) (2002) 4367-4372.

[112] H.Q. Miao, R. Ishai-Michaeli, R. Atzmon, T. Peretz, I. Vlodavsky, Sulfate moieties in the subendothelial extracellular matrix are involved in basic fibroblast growth factor sequestration, dimerization, and stimulation of cell proliferation, J. Biol. Chem. 271 (9) (1996) 4879-4886.

[113] Herbert C., Lassalle G., Alcouffe C., Bono F., Approaches targeting the FGF-FGFR system: a review of the recent patent literature and associated advanced therapeutic agents, Pharmaceutical patent analyst, 2014, 3, 6, 585-612 Epub 2014/12/10.

[114] M. Rusnati, M. Presta, Extracellular angiogenic growth factor interactions: an angiogenesis interactome survey, Endothelium 13 (2) (2006) 93-111 (Epub 2006/05/27)

[115] M. Rusnati, M. Presta, Angiogenic growth factors interactome and drug discovery: the contribution of surface plasmon resonance, Cytokine Growth Factor Rev. (2014) (Epub 2014/12/04)

[116] G. Taraboletti, M. Rusnati, L. Ragona, G. Colombo, Targeting tumor angiogenesis with TSP-1-based compounds: rational design of antiangiogenic mimetics of endogenous inhibitors, Oncotarget 1 (7) (2010) 662-673 (Epub 2011/02/15).

[117] X. Guillonneau, F. Regnier-Ricard, O. Laplace, L. Jonet, M. Bryckaert, Y. Courtois, et al., Fibroblast growth factor (FGF) soluble receptor 1 acts as a natural inhibitor of FGF2 neurotrophic activity during retinal degeneration, Mol. Biol. Cell 9 (10) (1998) 2785-2802 (Epub 1998/10/08).

[118] D. Leali, R. Bianchi, A. Bugatti, S. Nicoli, S. Mitola, L. Ragona, et al., Fibroblast growth factor 2-antagonist activity of a long-pentraxin 3-derived anti-angiogenic pentapeptide, J. Cell. Mol. Med. 14 (8) (2010) 2109-2121 (Epub 2009/07/25).

[119] A. Giacomini, S. Matarazzo, K. Pagano, L. Ragona, S. Rezzola, M. Corsini, et al., A long pentraxin-3-derived pentapeptide for the therapy of FGF8b-driven steroid hormone-regulated cancers, Oncotarget (2015), Epub 2015/04/29.

[120] R. Ronca, A. Giacomini, E. Di Salle, D. Coltrini, K. Pagano, L. Ragona, et al., Long-pentraxin 3 derivative as a small-Molecule FGF trap for cancer therapy, Cancer Cell 28 (2) (2015) 225-239.

[121] M. Rusnati, P. Oreste, G. Zoppetti, M. Presta, Biotechnological engineering of heparin/heparan sulphate: a novel area of multi-target drug discovery, Curr. Pharm. Des. 11 (19) (2005) 2489-2499 (Epub 2005/07/20).

[122] M. Presta, D. Leali, H. Stabile, R. Ronca, M. Camozzi, L. Coco, et al., Heparin derivatives as angiogenesis inhibitors, Curr. Pharm. Des. 9 (7) (2003) $553-566$.

[123] A. Eggert, N. Ikegaki, J. Kwiatkowski, H. Zhao, G.M. Brodeur, B.P. Himelstein, High-level expression of angiogenic factors is associated with advanced tumor stage in human neuroblastomas, Clin. Cancer Res. 6 (5) (2000) 1900-1908.

[124] T.C. Harding, L. Long, S. Palencia, H. Zhang, A. Sadra, K. Hestir, et al., Blockade of nonhormonal fibroblast growth factors by FP-1039 inhibits growth of multiple types of cancer, Sci. Trans. Med. 5 (178)(2013) 178ra39 (Epub 2013/03/29).

[125] M. Rusnati, P. Dell'Era, C. Urbinati, E. Tanghetti, M.L. Massardi, Y. Nagamine, et al., A distinct basic fibroblast growth factor (FGF-2)/FGF receptor interaction distinguishes urokinase-type plasminogen activator induction from mitogenicity in endothelial cells, Mol. Biol. Cell 7 (3) (1996) 369-381.

[126] X. Chen, X. Wang, Y. Wang, L. Yang, J. Hu, W. Xiao, et al., Improved tumor-targeting drug delivery and therapeutic efficacy by cationic liposome modified with truncated bFGF peptide, J. Control. Release 145 (1) (2010) 17-25 (Epub 2010/03/24)

[127] Q.M. He, Y.Q. Wei, L. Tian, X. Zhao, J.M. Su, L. Yang, et al., Inhibition of tumor growth with a vaccine based on xenogeneic homologous fibroblast growth factor receptor-1 in mice, J. Biol. Chem. 278 (24) (2003) 21831-21836 (Epub 2003/03/26)

[128] A. Schilling-Schon, U. Pleyer, C. Hartmann, P.W. Rieck, The role of endogenous growth factors to support corneal endothelial migration after wounding in vitro, Exp. Eye Res. 71 (6) (2000) 583-589.

[129] R. Ronca, P. Benzoni, D. Leali, C. Urbinati, M. Belleri, M. Corsini, et al., Antiangiogenic activity of a neutralizing human single-chain antibody fragment against fibroblast growth factor receptor 1, Mol. Cancer Ther. 9 (12) (2010) 3244-3253.

[130] R. Ronca, P. Benzoni, A. De Luca, E. Crescini, P. Dell'era, Phage displayed peptides/antibodies recognizing growth factors and their tyrosine kinase receptors as tools for anti-cancer therapeutics, Int. J. Mol. Sci. 13 (4) (2012) 5254-5277 (Epub 2012/05/19)

[131] M. Presta, M. Rusnati, C. Urbinati, A. Sommer, G. Ragnotti, Biologically active synthetic fragments of human basic fibroblast growth factor (bFGF): identification of two Asp-Gly-Arg-containing domains involved in the mitogenic activity of bFGF in endothelial cells, J. Cell. Physiol. 149 (3) (1991) $512-524$

[132] M. Rusnati, E. Tanghetti, P. Dell'Era, A. Gualandris, M. Presta, alphavbeta3 integrin mediates the cell-adhesive capacity and biological activity of basic fibroblast growth factor (FGF-2) in cultured endothelial cells, Mol. Biol. Cel 8 (12) (1997) 2449-2461. 
[133] C.C. Kumar, M. Malkowski, Z. Yin, E. Tanghetti, B. Yaremko, T. Nechuta, et al., Inhibition of angiogenesis and tumor growth by SCH221153, a dual alpha(v)beta3 and alpha(v)beta5 integrin receptor antagonist, Cancer Res. 61 (5) (2001) 2232-2238.

[134] M. Friedlander, P.C. Brooks, R.W. Shaffer, C.M. Kincaid, J.A. Varner, D.A. Cheresh, Definition of two angiogenic pathways by distinct alpha $\mathrm{V}$ integrins, Science 270 (5241) (1995) 1500-1502.

[135] C.H. Yeh, H.C. Peng, R.S. Yang, T.F. Huang, Rhodostomin, a snake venom disintegrin, inhibits angiogenesis elicited by basic fibroblast growth factor and suppresses tumor growth by a selective alpha(v)beta(3) blockade of endothelial cells, Mol. Pharmacol. 59 (5) (2001) 1333-1342.

[136] X. Lin, K. Takahashi, S.L. Campion, Y. Liu, G.G. Gustavsen, L.A. Pena, et al., Synthetic peptide F2A4-K-NS mimics fibroblast growth factor-2 in vitro and is angiogenic in vivo, Int. J. Mol. Med. 17 (5) (2006) 833-839 (Epub 2006/04/06)

[137] S. Hibino, M. Shibuya, M.P. Hoffman, J.A. Engbring, R. Hossain, M. Mochizuki, et al., Laminin alpha5 chain metastasis- and angiogenesis-inhibiting peptide blocks fibroblast growth factor 2 activity by binding to the heparan sulfate chains of CD44, Cancer Res. 65 (22) (2005) 10494-10501 (Epub 2005/11/17).

[138] J.S. Mader, D. Smyth, J. Marshall, D.W. Hoskin, Bovine lactoferricin inhibits basic fibroblast growth factor- and vascular endothelial growth factor165-induced angiogenesis by competing for heparin-like binding sites on endothelial cells, Am. J. Pathol. 169 (5) (2006) 1753-1766 (Epub 2006/10/31).

[139] G. Neufeld, D. Gospodarowicz, Protamine sulfate inhibits mitogenic activities of the extracellular matrix and fibroblast growth factor, but potentiates that of epidermal growth factor, J. Cell. Physiol. 132 (2) (1987) 287-294.

[140] K.J. Brown, C.R. Parish, Histidine-rich glycoprotein and platelet factor 4 mask heparan sulfate proteoglycans recognized by acidic and basic fibroblast growth factor, Biochemistry 33 (46) (1994) 13918-13927.

[141] W. Zhang, R. Swanson, G. Izaguirre, Y. Xiong, L.F. Lau, S.T. Olson, The heparin-binding site of antithrombin is crucial for antiangiogenic activity, Blood 106 (5) (2005) 1621-1628 (Epub 2005/05/21).

[142] V. Knights, S.J. Cook, De-regulated FGF receptors as therapeutic targets in cancer, Pharmacol. Ther. 125 (1) (2010) 105-117 (Epub 2009/10/31).

[143] G. Aprile, M. Macerelli, F. Giuliani, Regorafenib for gastrointestinal malignancies: from preclinical data to clinical results of a novel multi-target inhibitor, BioDrugs: Clin. Immunother. Biopharm. Gene Ther. 27 (3) (2013) 213-224 (Epub 2013/02/26).

[144] F. Hilberg, G.J. Roth, M. Krssak, S. Kautschitsch, W. Sommergruber, U. Tontsch-Grunt, et al., BIBF 1120: triple angiokinase inhibitor with sustained receptor blockade and good antitumor efficacy, Cancer Res. 68 (12) (2008) 4774-4782 (Epub 2008/06/19).

[145] J.M. Gozgit, M.J. Wong, L. Moran, S. Wardwell, Q.K. Mohemmad, N.I. Narasimhan, et al., Ponatinib (AP24534), a multitargeted pan-FGFR inhibitor with activity in multiple FGFR-amplified or mutated cancer models, Mol. Cancer Ther. 11 (3) (2012) 690-699 (Epub 2012/01/13).

[146] M.V. Dieci, M. Arnedos, F. Andre, J.C. Soria, Fibroblast growth factor receptor inhibitors as a cancer treatment: from a biologic rationale to medical perspectives, Cancer Discov. 3 (3) (2013) 264-279 (Epub 2013/02/19).

[147] Y. Zhao, A.A. Adjei, Targeting angiogenesis in cancer therapy: moving beyond vascular endothelial growth factor, Oncologist 20 (6) (2015) 660-673 (Epub 2015/05/24).

[148] F. Bono, F. De Smet, C. Herbert, K. De Bock, M. Georgiadou, P. Fons, et al., Inhibition of tumor angiogenesis and growth by a small-molecule multi-FGF receptor blocker with allosteric properties, Cancer Cell 23 (4) (2013) 477-488 (Epub 2013/04/20).

[149] G. Liang, G. Chen, X. Wei, Y. Zhao, X. Li, Small molecule inhibition of fibroblast growth factor receptors in cancer, Cytokine Growth Factor Rev. 24 (5) (2013) 467-475 (Epub 2013/07/09).

[150] A.N. Brooks, E. Kilgour, P.D. Smith, Molecular pathways: fibroblast growth factor signaling: a new therapeutic opportunity in cancer, Clin. Cancer Res. 18 (7) (2012) 1855-1862 (Epub 2012/03/06).

[151] G. Liang, Z. Liu, J. Wu, Y. Cai, X. Li, Anticancer molecules targeting fibroblast growth factor receptors, Trends Pharmacol. Sci. 33 (10) (2012) 531-541 (Epub 2012/08/14).

[152] M. Katoh, H. Nakagama, FGF receptors: cancer biology and therapeutics, Med. Res. Rev. 34 (2) (2014) 280-300 (Epub 2013/05/23).

[153] H.K. Ho, A.H. Yeo, T.S. Kang, B.T. Chua, Current strategies for inhibiting FGFR activities in clinical applications: opportunities, challenges and toxicological considerations, Drug Discov. Today 19 (1) (2014) 51-62 (Epub 2013/08/13).

[154] O. Casanovas, D.J. Hicklin, G. Bergers, D. Hanahan, Drug resistance by evasion of antiangiogenic targeting of VEGF signaling in late-stage pancreatic islet tumors, Cancer Cell 8 (4) (2005) 299-309 (Epub 2005/10/18).

[155] C. Lieu, J. Heymach, M. Overman, H. Tran, S. Kopetz, Beyond VEGF: inhibition of the fibroblast growth factor pathway and antiangiogenesis, Clin. Cancer Res. 17 (19) (2011) 6130-6139 (Epub 2011/09/29).

[156] H.D. Sun, M. Malabunga, J.R. Tonra, R. DiRenzo, F.E. Carrick, H. Zheng, et al., Monoclonal antibody antagonists of hypothalamic FGFR1 cause potent but reversible hypophagia and weight loss in rodents and monkeys, Am. J. Physiol. Endocrinol. Metab. 292 (3) (2007) E964-E976 (Epub 2006/11/30).

[157] A.P. Brown, C.L. Courtney, L.M. King, S.C. Groom, M.J. Graziano, Cartilage dysplasia and tissue mineralization in the rat following administration of a FGF receptor tyrosine kinase inhibitor, Toxicol. Pathol. 33 (4) (2005) 449-455 (Epub 2005/07/23).
[158] X. Han, Z. Xiao, L.D. Quarles, Membrane and integrative nuclear fibroblastic growth factor receptor (FGFR) regulation of FGF-23, J. Biol. Chem. 290 (16) (2015) 10447-10459 (Epub 2015/03/11).

[159] M. Presta, M. Rusnati, M. Belleri, L. Morbidelli, M. Ziche, D. Ribatti, Purine analogue 6-methylmercaptopurine riboside inhibits early and late phases of the angiogenesis process, Cancer Res. 59 (10) (1999) 2417-2424 (Epub 1999/05/27).

[160] A. Nakashio, N. Fujita, T. Tsuruo, Topotecan inhibits VEGF- and bFGF-induced vascular endothelial cell migration via downregulation of the PI3K-Akt signaling pathway, Int. J. Cancer 98 (1) (2002) 36-41 (Epub 2002/02/22).

[161] J. Fujimoto, M. Hori, S. Ichigo, R. Hirose, T. Tamaya, Antiestrogenic compounds inhibit estrogen-induced expressions of basic fibroblast growth factor and its mRNA in well-differentiated endometrial cancer cells, Gen. Pharmacol. 28 (2) (1997) 215-219 (Epub 1997/02/01).

[162] A.R. Gagliardi, B. Hennig, D.C. Collins, Antiestrogens inhibit endothelial cell growth stimulated by angiogenic growth factors, Anticancer Res. 16 (3A) (1996) 1101-1106 (Epub 1996/05/01).

[163] A. De Luisi, A. Ferrucci, A.M. Coluccia, R. Ria, M. Moschetta, E. de Luca, et al., Lenalidomide restrains motility and overangiogenic potential of bone marrow endothelial cells in patients with active multiple myeloma, Clin. Cancer Res. 17 (7) (2011) 1935-1946 (Epub 2011/02/11).

[164] K. Keledjian, J.B. Garrison, N. Kyprianou, Doxazosin inhibits human vascular endothelial cell adhesion, migration, and invasion, J. Cell. Biochem. 94 (2) (2005) 374-388 (Eub 2004/11/05).

[165] M. Presta, M. Belleri, A. Vacca, D. Ribatti, Anti-angiogenic activity of the purine analog 6-thioguanine, Leukemia 16 (8) (2002) 1490-1499 (Epub 2002/07/30).

[166] K. Shailubhai, S. Dheer, D. Picker, G. Kaur, E.A. Sausville, G.S. Jacob, Atiprimod is an inhibitor of cancer cell proliferation and angiogenesis, J. Exp. Ther. Oncol. 4 (4) (2004) 267-279 (Epub 2005/04/23).

[167] R.J. Young, A.W. Tin, N.J. Brown, M. Jitlal, S.M. Lee, P.J. Woll, Analysis of circulating angiogenic biomarkers from patients in two phase III trials in lung cancer of chemotherapy alone or chemotherapy and thalidomide, Br. J. Cancer 106 (6) (2012) 1153-1159 (Epub 2012/02/23).

[168] K. Harada, Supriatno, Y. Kawashima, H. Yoshida, M. Sato, S-1 inhibits tumorigenicity and angiogenesis of human oral squamous cell carcinoma cells by suppressing expression of phosphorylated Akt, vascular endothelial growth factor and fibroblast growth factor-2, Int. J. Oncol. 30 (2) (2007) 365-374 (Epub 2007/01/05).

[169] S. Koyama, H. Takagi, A. Otani, K. Suzuma, K. Nishimura, Y. Honda, Tranilast inhibits protein kinase C-dependent signalling pathway linked to angiogenic activities and gene expression of retinal microcapillary endothelial cells, $\mathrm{Br}$. J. Pharmacol. 127 (2) (1999) 537-545 (Epub 1999/06/29).

[170] N. Klauber, F. Browne, B. Anand-Apte, R.J. D’Amato, New activity of spironolactone. Inhibition of angiogenesis in vitro and in vivo, Circulation 94 (10) (1996) 2566-2571 (Epub 1996/11/15).

[171] G. Ferretti, A. Fabi, P. Carlini, P. Papaldo, P. Cordiali Fei, S. Di Cosimo, et al., Zoledronic-acid-induced circulating level modifications of angiogenic factors, metalloproteinases and proinflammatory cytokines in metastatic breast cancer patients, Oncology 69 (1) (2005) 35-43 (Epub 2005/08/10).

[172] S. Liekens, J. Neyts, E. De Clercq, E. Verbeken, D. Ribatti, M. Presta, Inhibition of fibroblast growth factor-2-induced vascular tumor formation by the acyclic nucleoside phosphonate cidofovir, Cancer Res. 61 (13) (2001) 5057-5064 (Epub 2001/06/30).

[173] R. Pai, I.L. Szabo, H. Kawanaka, B.A. Soreghan, M.K. Jones, A.S. Tarnawski, Indomethacin inhibits endothelial cell proliferation by suppressing cell cycle proteins and PRB phosphorylation: a key to its antiangiogenic action? Mol. Cell Biol. Res. Commun.: MCBRC 4 (2) (2000) 111-116 (Epub 2001/02/15).

[174] K.M. Leahy, R.L. Ornberg, Y. Wang, B.S. Zweifel, A.T. Koki, J.L. Masferrer, Cyclooxygenase-2 inhibition by celecoxib reduces proliferation and induces apoptosis in angiogenic endothelial cells in vivo, Cancer Res. 62 (3) (2002) 625-631 (Epub 2002/02/07).

[175] L. Vincent, W. Chen, L. Hong, F. Mirshahi, Z. Mishal, T. Mirshahi-Khorassani, et al., Inhibition of endothelial cell migration by cerivastatin, an HMG-CoA reductase inhibitor: contribution to its anti-angiogenic effect, FEBS Lett. 495 (3) (2001) 159-166 (Epub 2001/05/04).

[176] C. Klein-Soyer, J.P. Cazenave, J.M. Herbert, J.P. Maffrand, SR 25989 inhibits healing of a mechanical wound of confluent human saphenous vein endothelial cells which is modulated by standard heparin and growth factors, J. Cell. Physiol. 160 (2) (1994) 316-322 (Epub 1994/08/01).

[177] U.H. Spandau, G. Sauder, U. Schubert, H.P. Hammes, J.B. Jonas, Effect of triamcinolone acetonide on proliferation of retinal endothelial cells in vitro and in vivo, Br. J. Ophthalmol. 89 (6) (2005) 745-747 (Epub 2005/06/01).

[178] W. Chen, L. Li, J. Zhu, J. Liu, J. Soria, C. Soria, et al., Control of angiogenesis by inhibitor of phospholipase A2, Chin. Med. Sci. J. Chung-kuo i hsueh k'o hsueh tsa chih/Chin. Acad. Med. Sci. 19 (1) (2004) 6-12 (Epub 2004/04/24).

[179] R. Mohan, J. Sivak, P. Ashton, L.A. Russo, B.Q. Pham, N. Kasahara, et al., Curcuminoids inhibit the angiogenic response stimulated by fibroblast growth factor-2 including expression of matrix metalloproteinase gelatinase B, J. Biol. Chem. 275 (14) (2000) 10405-10412 (Epub 2000/04/01).

[180] M.R. Sartippour, D. Heber, L. Zhang, P. Beatty, D. Elashoff, R. Elashoff, et al. Inhibition of fibroblast growth factors by green tea, Int. J. Oncol. 21 (3) (2002) 487-491 (Epub 2002/08/09).

[181] D. Lu, Y. Xia, B. Tong, C. Zhang, R. Pan, H. Xu, et al., In vitro anti-angiogenesis effects and active constituents of the saponin fraction from Gleditsia sinensis, Integr. Cancer Ther. 13 (5) (2014) 446-457 (Epub 2012/04/17). 
[182] J.E. Huh, E.O. Lee, M.S. Kim, K.S. Kang, C.H. Kim, B.C. Cha, et al., Penta-O-galloyl-beta-D-glucose suppresses tumor growth via inhibition of angiogenesis and stimulation of apoptosis: roles of cyclooxygenase-2 and mitogen-activated protein kinase pathways, Carcinogenesis 26 (8) (2005) 1436-1445 (Epub 2005/04/23).

[183] K.S. Jeon, H.J. Na, Y.M. Kim, H.J. Kwon, Antiangiogenic activity of 4-0-methylgallic acid from Canavalia gladiata, a dietary legume, Biochem. Biophys. Res. Commun. 330 (4) (2005) 1268-1274 (Eub 2005/04/13).

[184] M. Belleri, D. Ribatti, S. Nicoli, F. Cotelli, L. Forti, V. Vannini, et al., Antiangiogenic and vascular-targeting activity of the microtubule-destabilizing trans-resveratrol derivative 3,5,4'-trimethoxystilbene, Mol. Pharmacol. 67 (5) (2005) 1451-1459 (Eub 2005/02/11).

[185] S.H. Lee, J. Lee, M.H. Jung, Y.M. Lee, Glyceollins, a novel class of soy phytoalexins, inhibit angiogenesis by blocking the VEGF and bFGF signaling pathways, Mol. Nutr. Food Res. 57 (2) (2013) 225-234 (Eub /12/12)

[186] A.S. Mousa, S.A. Mousa, Anti-angiogenesis efficacy of the garlic ingredient alliin and antioxidants: role of nitric oxide and p53, Nutr. Cancer 53 (1) (2005) 104-110 (Epub 2005/12/15).

[187] S. Hussain, M. Slevin, N. Ahmed, D. West, M.I. Choudhary, H. Naz, et al., Stilbene glycosides are natural product inhibitors of FGF-2-induced angiogenesis, BMC Cell Biol. 10 (2009) 30 (Epub 2009/04/25).

[188] Y. Zhang, L. Wang, Y. Chen, C. Qing, Anti-angiogenic activity of salvicine, Pharm. Biol. 51 (8) (2013) 1061-1065 (Epub 2013/06/12).

[189] K. Kunimasa, M. Ikekita, M. Sato, T. Ohta, Y. Yamori, M. Ikeda, et al., Nobiletin, a citrus polymethoxyflavonoid, suppresses multiple angiogenesis-related endothelial cell functions and angiogenesis in vivo, Cancer Sci. 101 (11) (2010) 2462-2469 (Epub 2010/07/31).
[190] G. Taraboletti, M. Poli, R. Dossi, L. Manenti, P. Borsotti, G.T. Faircloth, et al., Antiangiogenic activity of aplidine, a new agent of marine origin, $\mathrm{Br}$. J. Cancer 90 (12) (2004) 2418-2424 (Epub 2004/06/03).

[191] Y. Tong, X. Zhang, F. Tian, Y. Yi, Q. Xu, L. Li, et al., Philinopside A, a novel marine-derived compound possessing dual anti-angiogenic and anti-tumor effects, Int. J. Cancer 114 (6) (2005) 843-853 (Epub 2005/01/13).

[192] J.S. Shim, H.S. Lee, J. Shin, H.J. Kwon, A. Psammaplin, A marine natural product, inhibits aminopeptidase $\mathrm{N}$ and suppresses angiogenesis in vitro, Cancer Lett. 203 (2) (2004) 163-169 (Eub 2004/01/21)

[193] R. Hoffman, D. Sykes, Inhibition of binding of basic fibroblast growth factor to low and high affinity receptors by carrageenans, Biochem. Pharmacol. 45 (11) (1993) 2348-2351 (Epub 1993/06/09).

[194] P. Ganesan, K. Matsubara, T. Sugawara, T. Hirata, Marine algal carotenoids inhibit angiogenesis by down-regulating FGF-2-mediated intracellular signals in vascular endothelial cells, Mol. Cell. Biochem. 380 (1-2) (2013) 1-9 (Eub 2013/04/25).

[195] G. Zhang, D. Panigrahy, L.M. Mahakian, J. Yang, J.Y. Liu, K.S. Stephen Lee, et al., Epoxy metabolites of docosahexaenoic acid (DHA) inhibit angiogenesis, tumor growth, and metastasis, Proc. Natl. Acad. Sci. U. S. A 110 (16) (2013) 6530-6535 (Epub 2013/04/05).

[196] F. Pedrono, B. Saiag, J.P. Moulinoux, A.B. Legrand, 1-O-alkylglycerols reduce the stimulating effects of bFGF on endothelial cell proliferation in vitro, Cancer Lett. 251 (2) (2007) 317-322 (Epub 2007/01/09).

[197] E. Dupont, P. Falardeau, S.A. Mousa, V. Dimitriadou, M.C. Pepin, T. Wang, et al., Antiangiogenic and antimetastatic properties of Neovastat (AE-941), an orally active extract derived from cartilage tissue, Clin. Exp. Metastasis 19 (2) (2002) 145-153 (Epub 2002/04/20).

[198] M. Rusnati, M. Presta, Angiogenic growth factors interactome and drug discovery: the contribution of surface plasmon resonance, Cytokine Growth Factor Rev. 26 (3) (2015) 293-310 (Epub 2014/12/04). 